\section{El Fuerte de Lanteira (Granada). Análisis de una fortificación de alquería de época nazarí}

\section{The Lanteira's Fort (Granada). Analysis of a Nasrid qarya's fortification}

Miguel Jiménez Puertas*

Guillermo García-Contreras Ruiz

Luca Mattei

Grupo de Investigación Toponimia, Historia y Arqueología del Reino de Granada. Universidad de Granada

\section{Resumen}

La intervención arqueológica de apoyo a la restauración llevada a cabo en el torreón de época medieval conocido como «El Fuerte», situado en el pueblo de Lanteira (Granada), en la cara norte de Sierra Nevada, nos ha permitido analizar con detalle su estructura y las distintas técnicas constructivas utilizadas, así como datar la construcción en los siglos XIV o XV.

Aunque el objetivo fundamental ha sido describir las características de esta estructura de época nazarí, también hemos integrado su estudio en el contexto de la evolución del poblamiento medieval de su entorno, pero además hemos intentado aproximarnos a su dimensión social y política, en el contexto del debate histórico sobre el último Estado islámico peninsular, sometido a la presión militar castellana.

Palabras clave: Fortificaciones rurales, Torres de alquería, Técnicas constructivas, Al-Andalus, Reino nazarí de Granada

\begin{abstract}
The archaeological excavations carried out supporting the restoration of the medieval tower known as «El Fuerte» («The Fortress»), in the town of Lanteira (Granada, northern side of Sierra Nevada), has allowed to analyze in detail its structure and the different building techniques used, and also to date the construction of the building to the fourteenth or fifteenth centuries.

Although the main aim was to describe the characteristics of this structure of the Nasrid period, we have also integrated this study within the context of the evolution of the medieval settlements of the area. Besides, we have tried to address the social and political dimensions of this tower in the context of the historical debate on the last Islamic state in the peninsula under Castilian military pressure.
\end{abstract}

Keywords: rural fortifications, qarya towers, building techniques, Al-Andalus, Nasrid kingdom of Granada.

*jpuertas@ugr.es, garciacontreras@ugr.es, lucamattei@ugr.es

\section{INTRODUCCIÓN}

Las torres rurales constituyen seguramente uno de los elementos más claros del contraste entre la organización social andalusí y la feudal. Esta circunstancia se manifiesta con toda rotundidad cuando estas torres, que surgen en los asentamientos rurales andalusíes para defenderse de las incursiones de ejércitos cristianos, pasan, tras la conquista, a representar en muchos casos nuevos centros de control de los señores feudales sobre el mundo rural.

También son un claro ejemplo de perduración de profundas realidades de base en ambas sociedades, al menos entre los siglos XI y XV, en espacios muy alejados geográficamente, como pueden ser el valle del Ebro o el del Genil. En el ámbito andalusí, la construcción de torres rurales, en alquerías o en almunias, precede al avance territorial de los Estados feudales: las encontramos ya en el siglo XI o principios de siglo XII en los valles del $\mathrm{Ebro}^{1}$, del Henares $^{2}$ o del Tajo ${ }^{3}$, poco después surgen o se generalizan en tierras valencianas ${ }^{4} \mathrm{o}$ del valle del Guadalquivir ${ }^{5}$, mientras que a partir del siglo XIII las encontramos en el reino nazarí de Granada ${ }^{6}$. Pero en este caso, incluso, sólo son habituales en los espacios más expuestos a la frontera

${ }^{1}$ Julián M. Ortega Ortega: «La agricultura de los vencedores y la agricultura de los vencidos: la investigación de las transformaciones feudales de los paisajes agrarios en el valle del Ebro (siglos XII-XIII)", en Helena Kirchner (ed.), Por una arqueología agraria. Perspectivas de investigación sobre espacios agrarios en las sociedades medievales hispánicas, Oxford, BAR International Series 2062, 2010, pp. 123-145, espec. pp. 129-132.

${ }^{2}$ Ernesto García-Soto Mateos y Susana Ferrero Ros: «La atalaya islámica del «Cerro de la Quebrada» o «El Mirador del Cid» de Sigüenza y algunas consideraciones sobre las fortificaciones islámicas del nordeste de la provincia de Guadalajara» en Ernesto García-Soto, Miguel Ángel Valero y Juan Pablo Martínez (eds.) Actas del segundo simposio de Arqueología de Guadalajara, Madrid, 2008, pp. 265-278.

${ }^{3}$ César Pacheco Jiménez: «La fortificación en el valle del Tajo y el alfoz de Talavera entre los siglos XI y XV", Espacio, Tiempo y Forma (Serie III, Historia Medieval), 17 (2004), pp. 485-517.

${ }^{4}$ André Bazzana y Pierre Guichard: «Les tours de défense de la huerta de Valence au XIIIe siècle», Mélanges de la Casa de Velázquez, XIV (1978), pp. 73-105; Josep Torró: «Fortificaciones en Yibäl Balansiya. Una propuesta de secuencia», en Antonio Malpica Cuello (ed.): Castillos y territorio en Al-Andalus, Granada, 1998, pp. 385-418; José Luis Simón García: «Alquerías fortificadas del Vinalopó», en Francisco Javier Jover Maestre y Concepción Navarro Poveda (coord.): De la medina a la vila, Alicante, 2004, pp. 107-138; Pablo Rodríguez Navarro, La torre árabe observatorio en tierras valencianas. Tipología arquitectónica, Valencia, 2008, tesis doctoral (http://dspace.upv.es/xmlui/handle/10251/3542).

${ }^{5}$ Francisco Sánchez Villaespesa: «Las torres de la campiña de Córdoba en el siglo XIII. Un sistema de defensa de las comunidades rurales en época almohade», Qurtuba, 1 (1996), pp. 157-170; Antonio Martínez Castro: «Breves notas sobre la funcionalidad de las torres islámicas de la campiña de Córdoba» en Antiquitas, 15 (2003), pp. 79-83.

"Mariano Martín García: "Torres de alquería de la provincia de Granada», en Actas del Tercer Congreso Nacional de Historia de la Construcción, Sevilla, 2000, vol. II, pp. 651-664; Miguel Jiménez Puertas: «Asentamientos rurales y frontera: las torres de alquería del territorio de Loja en época nazarí», en Carmen Trillo San José (ed.), Asentamientos rurales y territorio en el Mediterráneo medieval, Granada, 2002, pp. 390-421. 


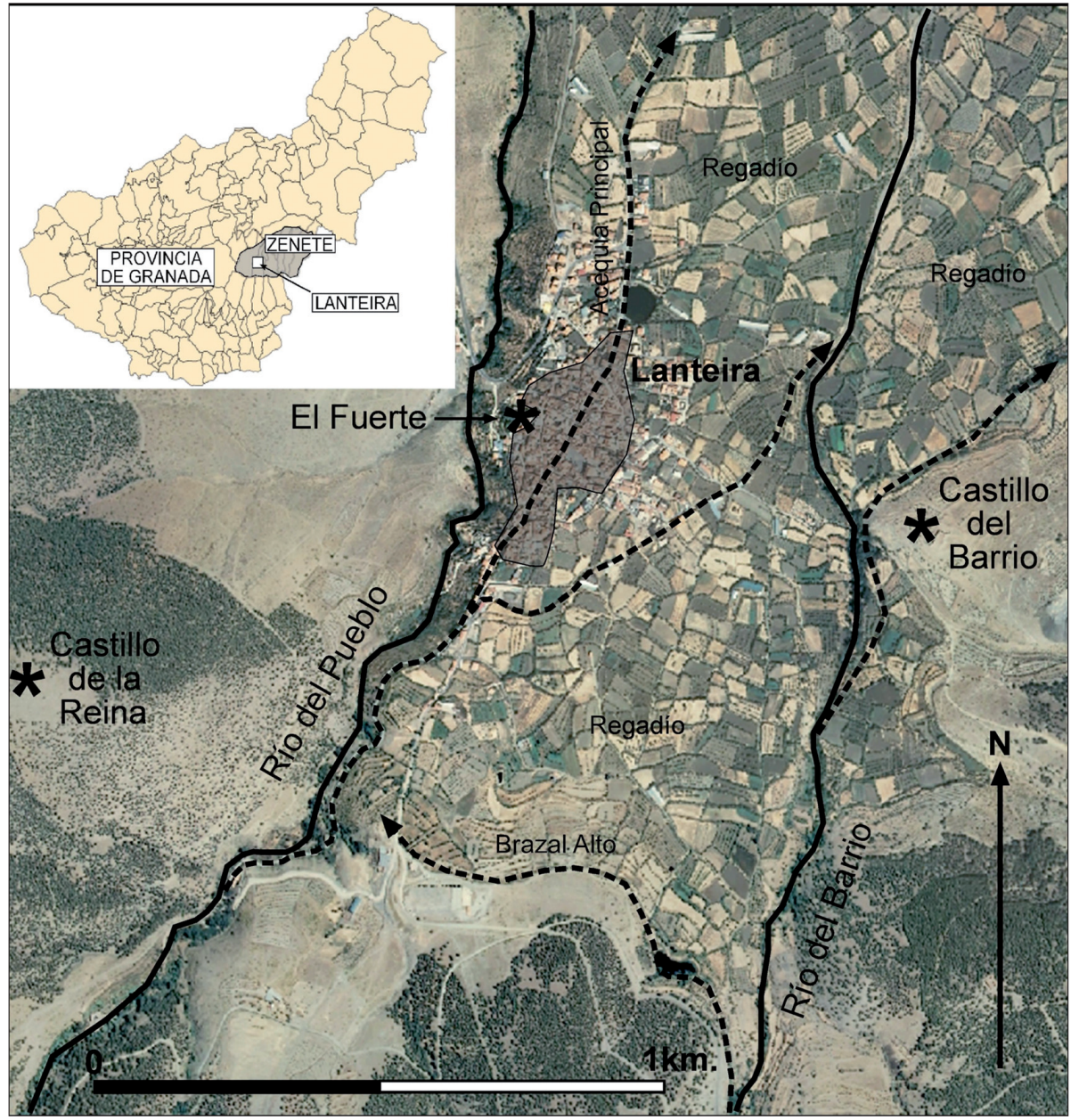

Fig. 1. Localización de Lanteira, con indicación de sus sistemas de regadío y las fortificaciones de época medieval de su entorno castellana, siendo escasas en amplias zonas. Por tanto, no se trata tanto de un fenómeno que genera la propia sociedad andalusí en todos los lugares, sino que responde sobre todo a un estímulo externo localizado geográficamente. Cuando este estímulo - las incursiones feudales de saqueo y destrucción - está presente, el mundo rural andalusí genera unas estructuras arquitectónicas similares — las torres - en distintos territorios y en distintos momentos, a pesar de la diversidad de soluciones concretas que encontramos en cuanto a las características de estas estructuras defensivas. No obstante, es también posible que en determinados contextos, los conflictos internos andalusíes, hayan dado lugar al surgimiento puntual de este tipo de fortificaciones.

Sin embargo, sabemos más de la apropiación feudal de algunas de estas torres, que de la iniciativa para su construcción o de su gestión en época andalusí. ¿Acaso tuvieron un carácter aristocrático también en esa época?, ¿qué papel tuvieron los Estados islámicos respecto a la construcción de estas torres: fomento, permisividad, oposición?, ¿cuál fue el de las comunidades campesinas?, ¿y el de las élites rurales? Las fuentes escritas nos informan de algunas cuestiones, como ciertas iniciativas de los emires para su construcción ${ }^{7}$ o su mantenimiento con bienes habices $^{8}$, pero será el análisis arqueológico el que tal vez pueda ofrecer más información sobre esta realidad que se impone en el mundo rural andalusí en contacto con las fronteras de los reinos cristianos feudales.

El cronista Mármol Carvajal atribuye al sultán nazarí Muhammad II (12731302) la construcción de varias torres en la Vega de Granada: «hizo cinco torres en el campo alderredor de la ciudad á la parte de la vega, donde se pudiesen recoger los Moros que andaban en las labores en tiempo de necesidad" (Luis del Mármol Carvajal: Historia del rebelion y castigo de los moriscos del reyno de Granada, Madrid, 1797, I, p. 25). Probablemente hace referencia a aquellas torres construidas en las alquerías del patrimonio real situadas en la Vega (Roma, Huécar, Cijuela, Asquerosa), de la que sólo se conserva la torre de Roma (Antonio Almagro Gorbea: «La torre de Romilla. Una torre nazarí en la Vega de Granada", Al-Qantara, XII (1991), pp. 225-250). Además se han conservado los restos de otras torres en la Vega de Granada (Alhendín, Gabia, Bordonal, etc.), aunque en estos casos no vinculadas al patrimonio real.

${ }^{8}$ Realidad que se documenta en el valle del Ebro a través de las fuentes árabes (Julián M. Ortega Ortega: «La agricultura de los vencedores...», p. 130), pero también lo refleja la documentación castellana respecto al reino nazarí, como es el caso de un documento de 1503, que hace referencia a los bienes habices de "las torres de las alcarias" (Pedro Hernández Benito: La Vega de Granada a fines de la Edad Media según las rentas de los habices, Granada, 1990, p. 113). 


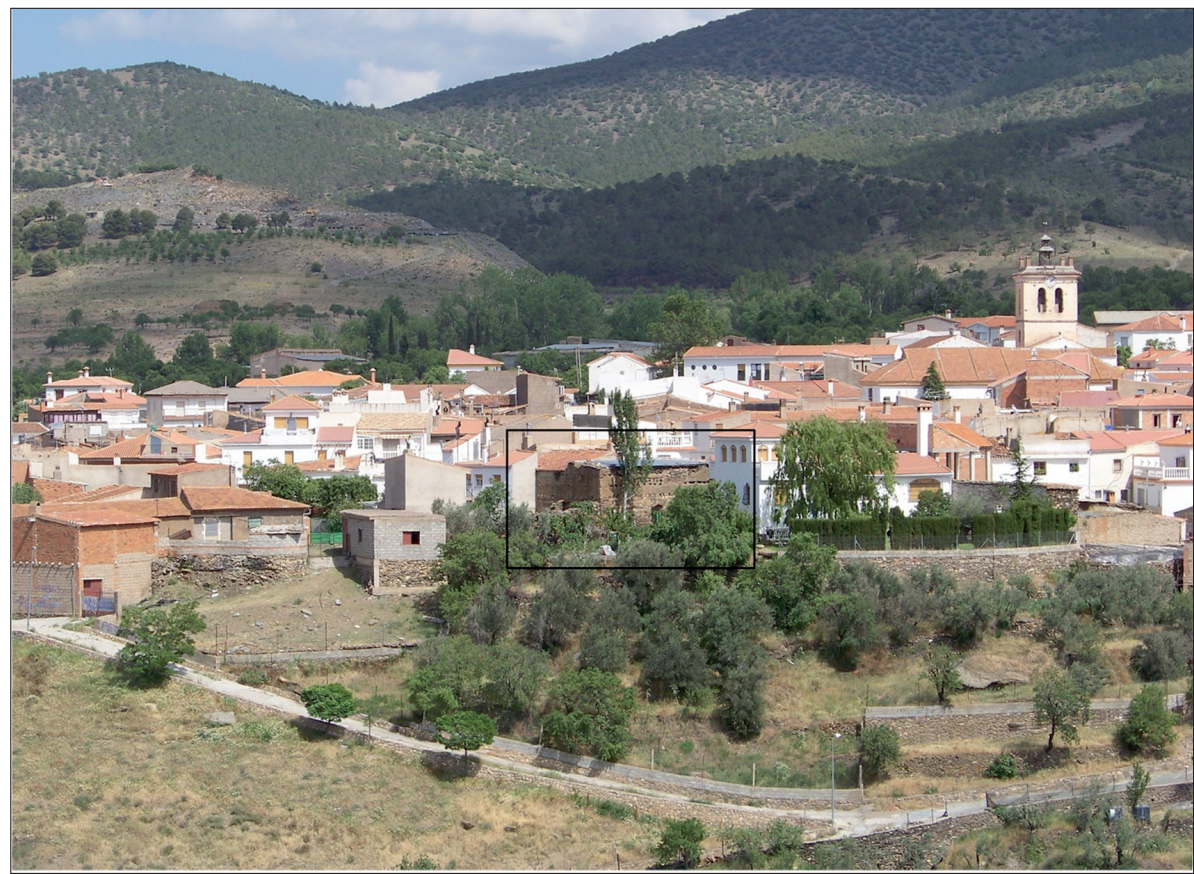

El conocimiento de estos edificios y de sus transformaciones tras la conquista feudal, junto al análisis espacial de su ubicación a diversas escalas, puede ofrecernos información de primera mano sobre si los cambios son de escaso calado o profundos, revelando en este caso, tal como viene planteando la historiografía, un cambio de función en el marco de un contexto social distinto. También si tras la conquista perduran muchas torres o sólo algunas, en concreto aquellas que se adaptan mejor a la nueva realidad social feudal. Además sería interesante comparar las torres andalusíes con otras fortificaciones señoriales de nueva planta de la misma época, para comprender mejor sus semejanzas y diferencias. Se trataría de ver hasta qué punto esta realidad material nos puede informar sobre el contraste entre ambas sociedades y, por tanto, arrojar más luz sobre el mundo rural andalusí y su evolución hasta la época nazarí.

Nuestra aportación a esta cuestión no pretende ser una visión general, sino que parte del análisis arqueológico de un caso concreto, una de las fortificaciones situadas en el pueblo de Lanteira, en la provincia de Granada. Se trata del torreón denominado "El Fuerte», si bien el edificio es más conocido en el pueblo como "La Sociedad», al haber sido la sede de una agrupación socialista antes de la Guerra Civil. Se trata de una estructura que se conserva parcialmente desmochada y en un estado de deterioro muy importante (Fig. 3), localizándose en el interior del casco urbano de la población, aunque en una zona periférica, junto a la ladera que baja de forma pronunciada hacia el río del Pueblo (Figs. 1 y 2). La intervención arqueológica de tipo puntual que hemos desarrollado en este torreón se ha llevado a cabo en el marco del proyecto de restauración de una parte del edificio, que es propiedad del Ayuntamiento, con la finalidad de darle un uso cultural. Lamentablemente no se pudo actuar en la otra parte que es de propiedad privada y que está incorporada a una casa colindante, lo que ha limitado las posibilidades de la investigación.

\section{EL CONTEXTO LOCAL: LA ALQUERÍA DE LANTEIRA Y LA EVOLUCIÓN DEL POBLAMIENTO MEDIEVAL EN SU ENTORNO 9}

La primera referencia a Lanteira en las fuentes escritas corresponde a la noticia relativa al nacimiento de Abū lHasan 'Alī b. Ahmad al-Gassānī en el año 547 H. / 1152-1153 J.C. en qaryat Aryantayra min Sanad Wādì $\bar{A} \breve{s}^{10}$, es decir en la alquería de Lanteira en el Zenete de Guadix. Sin embargo, sobre las características de esta alquería apenas tenemos más datos que los proporcionados por documentos castellanos posteriores a la conquis-

\footnotetext{
${ }^{9}$ Sobre la alquería de Lanteira, véase el trabajo más general de José María Martín Civantos: Poblamiento y territorio medieval en el Zenete (Granada), Granada, 2007, pp. 69-85, 264-274 y 389-404; así como una reflexión más específica en José María Martín Civantos, Miguel Jiménez Puertas y Guillermo GarcíaContreras Ruiz: «Sobre la caracterización de las alquerías en al-Andalus: el caso de Lanteira (Granada)", en X Jornadas de Arqueología Medieval: Paisajes Históricos y Arqueología Medieval (Granada, junio de 2009) (en prensa). De estos trabajos tomamos las referencias que se encuentran a continuación.

${ }^{10}$ José María Martín Civantos: Poblamiento y territorio..., p. 399.
} 


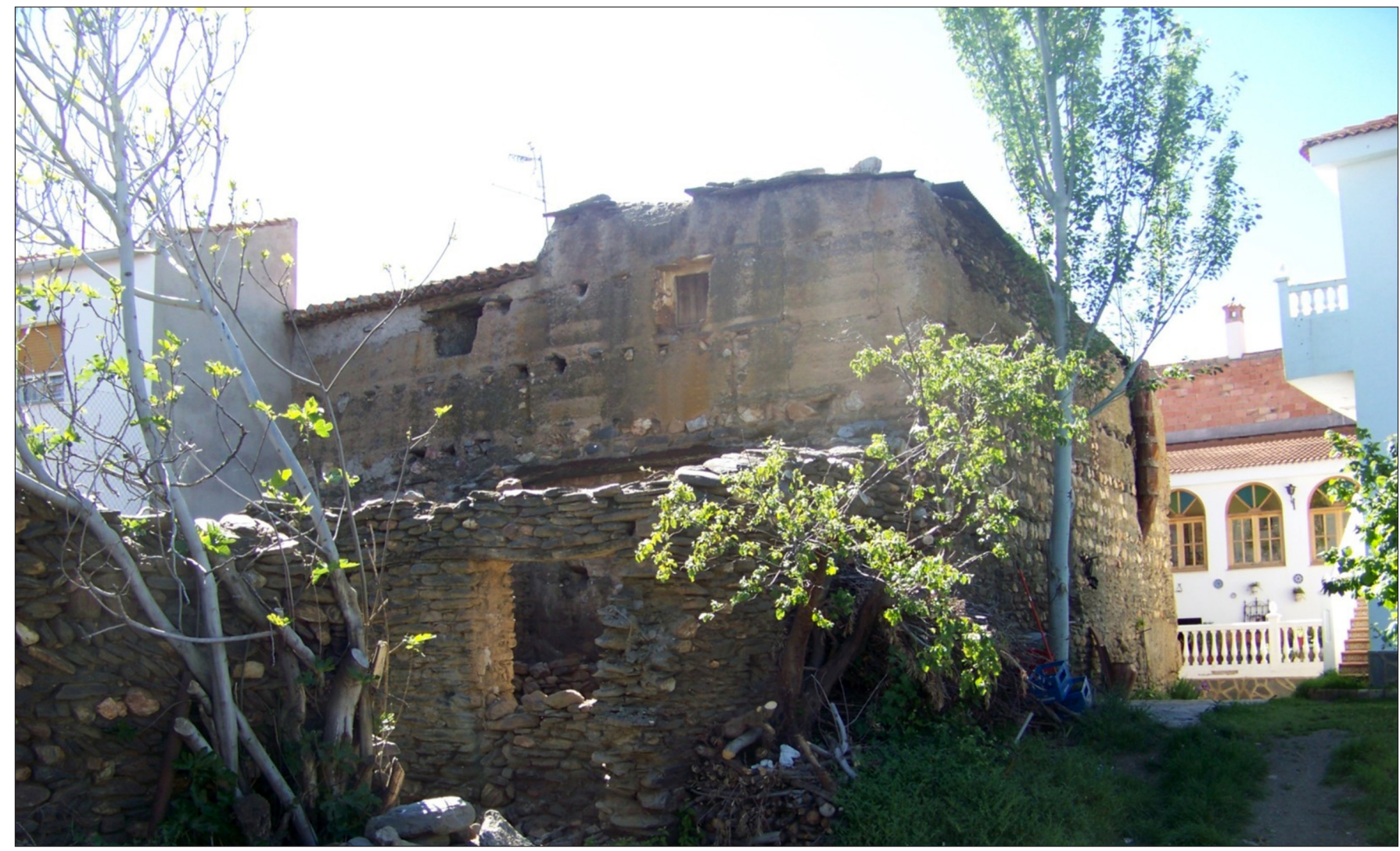

Fig. 3. Vista de El Fuerte de Lanteira

ta. En este sentido, hay que recordar que este lugar pasó a manos castellanas tras la caída de Guadix en diciembre de 1489 y casi inmediatamente pasó a formar parte de un amplio señorío, posteriormente conocido como Marquesado del Zenete, que abarcaba gran parte de las poblaciones del término de Guadix situadas al pie de Sierra Nevada, en su cara norte, en concreto, de oeste a este, las siguientes: Jérez y su barrio de Alcázar, Lanteira, Alquife, Aldeire, La Calahorra, Ferreira, Dólar y Huéneja. Se trata de un espacio donde la agricultura de regadío constituía la principal actividad económica, a pesar de la riqueza minera del subsuelo y de la abundancia de pastos. En todos estos lugares permaneció la población musulmana, mudéjar, aunque tras las conversiones de 1500 pasaron a tener el estatus de cristianos nuevos o moriscos, los cuales perduraron hasta la expulsión en 1570, tras su sublevación en gran parte del reino de Granada y una guerra que duró dos años. A este largo período mudéjar-morisco (1490-1570), en cierto modo transicional, donde conviven realidades antiguas y nuevas, corresponden la mayor parte de los datos que tenemos para intentar reconstruir las características de la alquería de Lanteira a finales de la época islámica.
En el momento inmediatamente posterior a la conquista, un documento de 1490 nos da la siguiente información sobre su población y rentas: "Llanteira, diçen que ay doçientos veçinos y que vale de renta çiento e veinte mill maravedis e mill fanegas de pan» ${ }^{11}$. Por tanto, vemos que se trata de una alquería muy poblada (unos 800 a 1.000 habitantes), que proporciona importantes rentas fiscales al Estado nazarí, tanto en especie como en moneda.

Hoy en día el pueblo de Lanteira constituye un núcleo concentrado, el único de su término municipal, pero se trata de una realidad que se impone a fines del siglo XVI, tras la expulsión de los moriscos. Con anterioridad a esta expulsión, según la documentación castellana, la alquería estaba formada por dos barrios algo distanciados el uno del otro, herencia del período islámico, como se deduce de la toponimia.

El barrio morisco de la Iglesia era conocido en época islámica como Harat al-Ŷamāa ('barrio de la mezquita aljama', Fardaximea o Hardagima en los documentos castellanos) y en él estaba tanto la iglesia, que debía ocupar la

\footnotetext{
${ }^{11}$ Archivo General de Simancas, Diversos de Castilla, legajo 44, documento 24
} (consultado en http:/pares.mcu.es). 


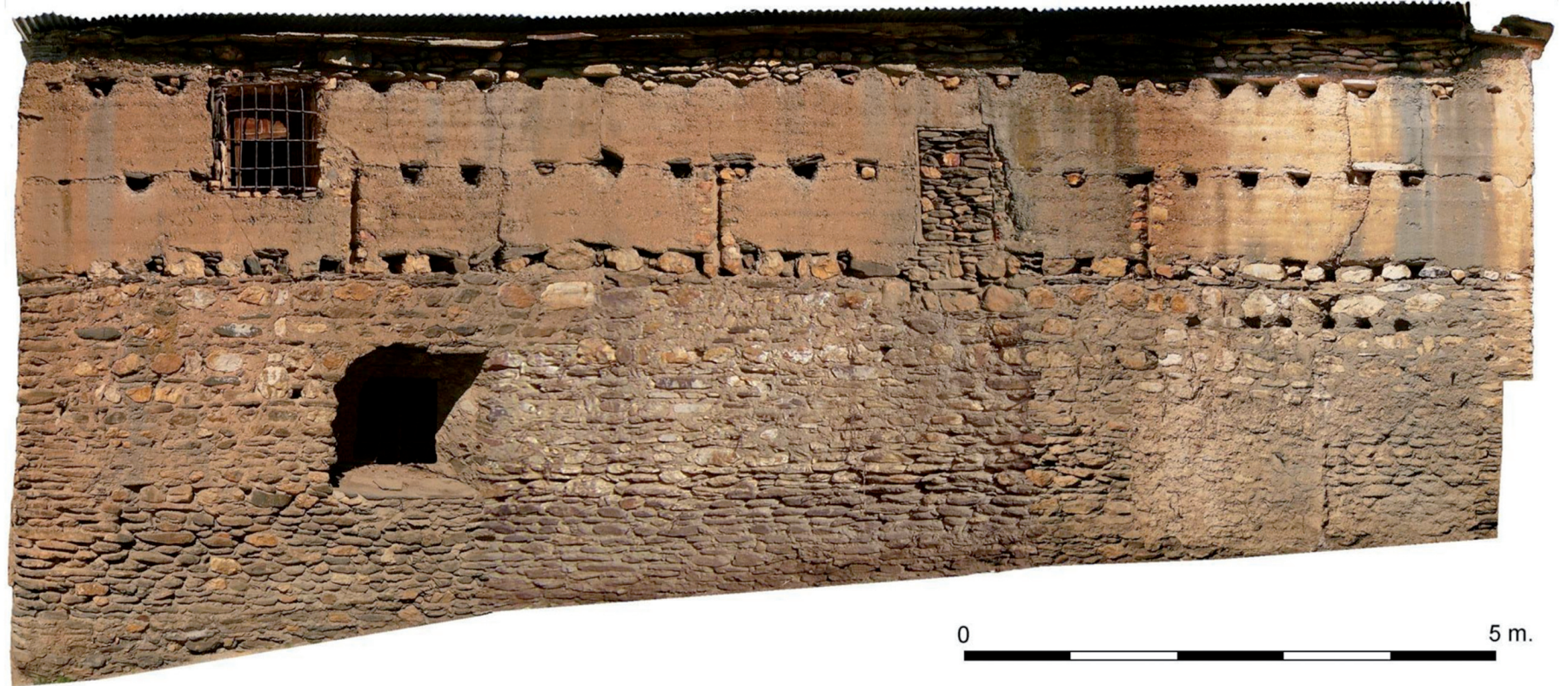

Fig. 4. Ortofotografía del exterior del muro perimetral sur (E2)

antigua mezquita transformada a principios del siglo XVI en templo cristiano, como un torreón, probablemente denominado El Borge (del árabe al-burŷ, 'la torre'), que posteriormente fue conocido como El Fuerte, a pesar de que probablemente estaba ya desmochado. Este barrio ha continuado habitado y constituye la base del actual núcleo de población, localizándose junto al río del Pueblo, en su margen derecha, cuyas aguas se utilizan para el riego, pasando la Acequia Madre por medio del lugar.

El otro barrio existente en época morisca se denominaba del Jarafí o de los Jarafis, quedando despoblado tras la expulsión de los cristianos nuevos. Su localización es posible gracias a la toponimia, dada la existencia del pago del Jarafí y del castillo del Barrio, localizados ambos a cierta distancia del barrio de la Mezquita, a algo más de 500 metros en dirección este, precisamente en la orilla derecha del río del Barrio, cuyas aguas se utilizan para regar el pago, compartiéndolas con el pueblo de Alquife, situado aguas abajo. No consta que existiese mezquita en este barrio, pero en cambio junto a él se construyó el baño nuevo en 1540, probablemente sobre los restos de un baño anterior. Además, otro dato significativo, es que aquí se localiza el ya citado castillo del Barrio, en realidad otra fortificación de alquería, a cuyos pies se localiza abundante cerámica de época almohade y nazarí, así como de primera época castellana, que debe de corresponder a la ubicación de las casas del barrio. El topónimo puede corresponder al árabe al-šaraf ('el cerro', 'el otero'); de hecho en el empadronamiento de 1550 se menciona un pago denominado del axarafe. Pero también puede hacer referencia, teniendo en cuenta también la versión en plural -barrio de los Jarafis_- a que sea un barrio habitado mayoritariamente por miembros de la familia o linajes de los Xarafis. En este sentido debemos destacar la mención en un documento de 1541 a "Hernando Xarafi, alguacil cobrador de la villa de Lanteira». Pero este topónimo, en cualquier caso, parece que es más reciente y se utiliza para englobar a otros barrios, ya sea aún existentes o abandonados, dado que un documento de 1511 alude a que este barrio del Jarafí estaba formado anteriormente por los de Benizahala y Benahaque, topónimos que se ha propuesto que podrían corresponder a asentamientos tribales de primera época islámica, por la existencia del prefijo beni- o bena-, del árabe banū ('hijos'). Estos topónimos se han vinculado con dos yacimientos situados también junto al río del Pueblo, en su margen derecha, pero algo más al norte del castillo del Barrio.

Llama la atención, en este caso de Lanteira, la existencia de dos barrios, o conjuntos de barrios, que tienen vegas diferenciadas e incluso fortificaciones distintas, aunque comparten la mezquita aljama. Pero esta realidad sobre las características de la alquería de Lanteira que refleja la documentación castellana posterior a la conquista, es el resultado de una compleja evolución del poblamiento medieval, que es necesario plantear, aunque sea brevemente.

Para el período altomedieval se ha documentado la ocupación de asentamientos ubicados en cerros y probablemente vinculados a actividades mineras, como es el caso del Cerro de las Minas, en época visigoda, y de la primera ocupación del Castillo de la Reina, en época emiral. En la 
margen derecha del río del Barrio se localizan tres asentamientos en ladera, sobre la acequia que riega estos campos, los cuales, como hemos visto, parecen vinculados a uno de los barrios de la alquería de Lanteira, el del Jarafí. La cronología que aporta la cerámica de prospección puede retrotraerse a época emiral en los dos situados más al norte, con un probable abandono hacia el siglo XII, pero en el situado más al sur, a los pies del Castillo del Barrio, la cronología parece abarcar del siglo XII al XVI, lo que tal vez refleje una reagrupación de estos barrios en torno a la citada fortificación. De todas formas, estas dataciones se basan en materiales de prospección, por lo cual hay que ser prudentes a la hora de valorarlas, al tiempo que tampoco conocemos con seguridad la cronología del castillo o fortificación del barrio del Jarafí.

Para la época bajomedieval, además de la alquería de Lanteira con sus barrios, aún debemos destacar la existencia de otro castillo próximo al barrio de la mezquita, en un elevado cerro sobre el margen izquierdo del río del Pueblo, con un probable barrio de casas anexo. Se trata del Castillo de la Reina (donde se constata una anterior ocupación emiral), que estuvo ocupado fundamentalmente en los siglos XII y XIII, como mucho hasta comienzos del XIV, teniendo en cuenta los materiales cerámicos visibles en superficie. Se ha propuesto explicar este asentamiento como resultado de un traslado de la población de la cercana alquería de Alcázar a raíz de las incursión aragonesa de 1125, por motivos de seguridad. No obstante, a pesar de su relativa proximidad a las vegas de Lanteira y Alcázar, parece una situación poco conveniente para una instalación permanente, y relativamente extendida en el tiempo, de una población dedicada a la agricultura de regadío, por el difícil acceso cotidiano y las dificultades de abastecimiento de agua (a pesar de la existencia de un aljibe). Por ello, tal vez deba interpretarse como un castillo rural con la doble funcionalidad de control estatal y refugio campesino, sin que esté todavía aclarada su vinculación con la actividad minera. Quizá su abandono se deba, o al menos coincide en el tiempo, a la proliferación de torres de alquería, dado que la torre de Alcázar parece construida en el siglo XIV y nuestra investigación ha mostrado que El Fuerte de Lanteira corresponde a los siglos XIV o XV.

\section{LA INTERVENCIÓN ARQUEOLÓGICA}

El espacio sobre el que se ha intervenido está formado por dos ámbitos diferenciados, el torreón propiamente dicho y un patio exterior anexo (Fig. 5). El torreón, que consta de dos pisos, tiene una planta ligeramente rectangular, con una superficie exterior de 203,00 $\mathrm{m}^{2}$, de los cuales corres-

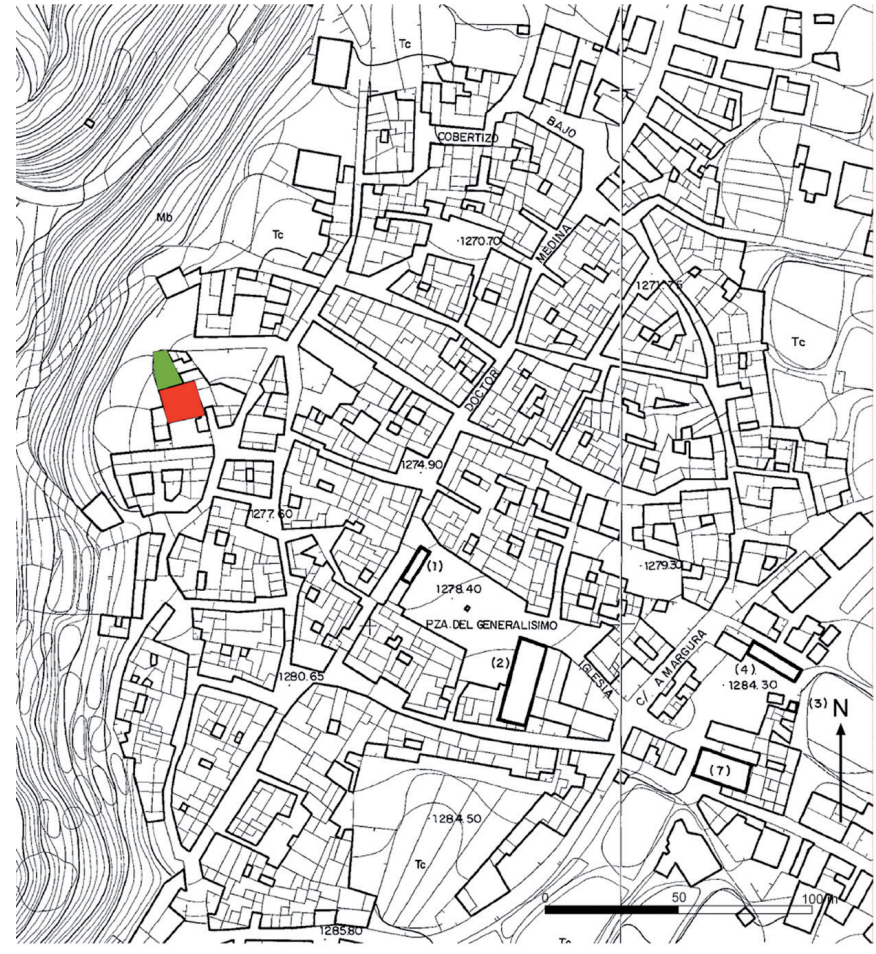

Fig. 5. Localización del torreón (rojo) y del patio exterior (verde) en el plano del pueblo de Lanteira

ponden al Ayuntamiento de Lanteira un total de 143,50 $\mathrm{m}^{2}$ en la planta baja y $127 \mathrm{~m}^{2}$ en la planta alta y el resto a un particular. La intervención se ha podido plantear únicamente en esta parte correspondiente al Ayuntamiento. Por lo que respecta al patio exterior, es de forma irregular y está situado junto a la cara Norte del torreón, teniendo una superficie de $88,50 \mathrm{~m}^{2}$. Se estructura en dos espacios, uno más próximo al torreón, donde se observan los muros de una habitación adosada, mientras que el otro espacio ha sido tradicionalmente un huerto, dividiendo ambas zonas un brazal de riego.

Para abordar la investigación de apoyo a la restauración de esta fortificación se ha planteado una doble actuación arqueológica, por una parte el análisis de las estructuras emergentes, por otra, la realización de una serie de sondeos arqueológicos.

El objetivo de la lectura estratigráfica de los muros y cubiertas ha sido documentar las distintas fases y técnicas constructivas utilizadas ${ }^{12}$. En ocasiones, como ocurre en el interior de la planta alta del edificio, se ha procedido a retirar los encalados y recubrimientos de los muros perime-

\footnotetext{
${ }^{12}$ En relación a esta temática véase el trabajo de Antonio Malpica Cuello: «Las técnicas constructivas en al-Andalus. Un debate entre la arqueología y la arquitectura», en Mercedes Durany, Francisco Javier Pérez y Beatriz Vaquero (eds.): Técnicas Agrícolas, Industriais e Constructivas na Idade Media, La Coruña, 1998, pp. 277-336.
} 


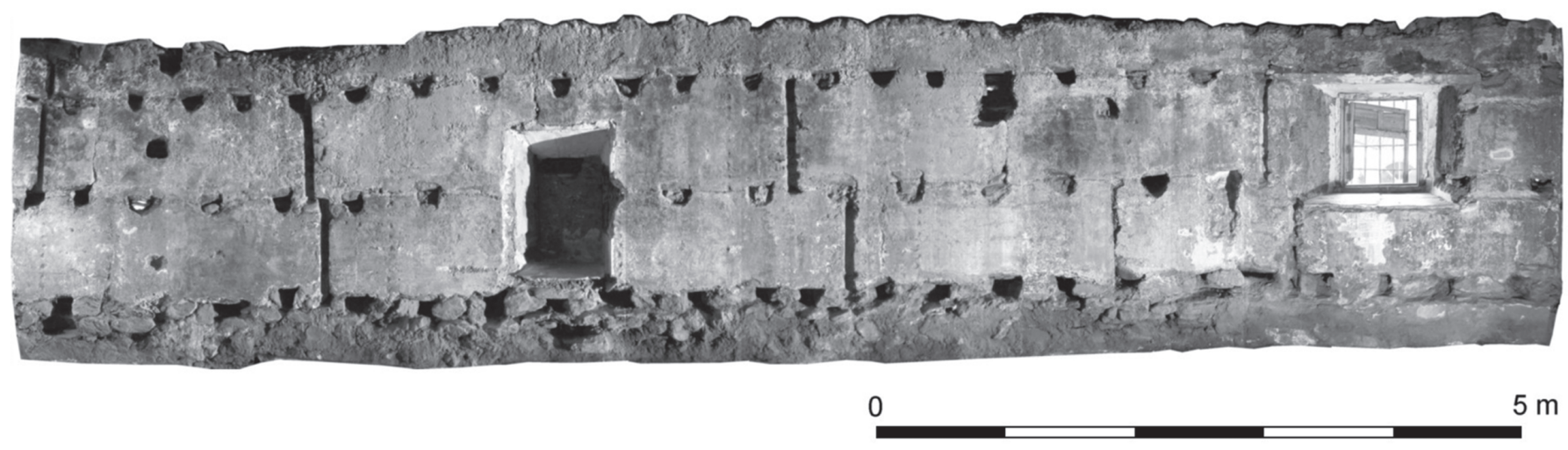

Fig. 6. Ortofotografía del interior de la planta alta del muro perimetral sur (E2)

trales, para poder analizar el tapial medieval de forma adecuada y observar su grado de conservación (Fig. 6). También se han realizado algunas catas en los revestimientos de otros muros en aquellos puntos que se han considerado de especial interés para aclarar la historia del edificio. Por ejemplo, se han seleccionado las uniones de distintos muros, así como los vanos abiertos en la fábrica, para determinar en uno y otro caso la secuencia de construcción de estos elementos y su calidad de obra original o reforma posterior.

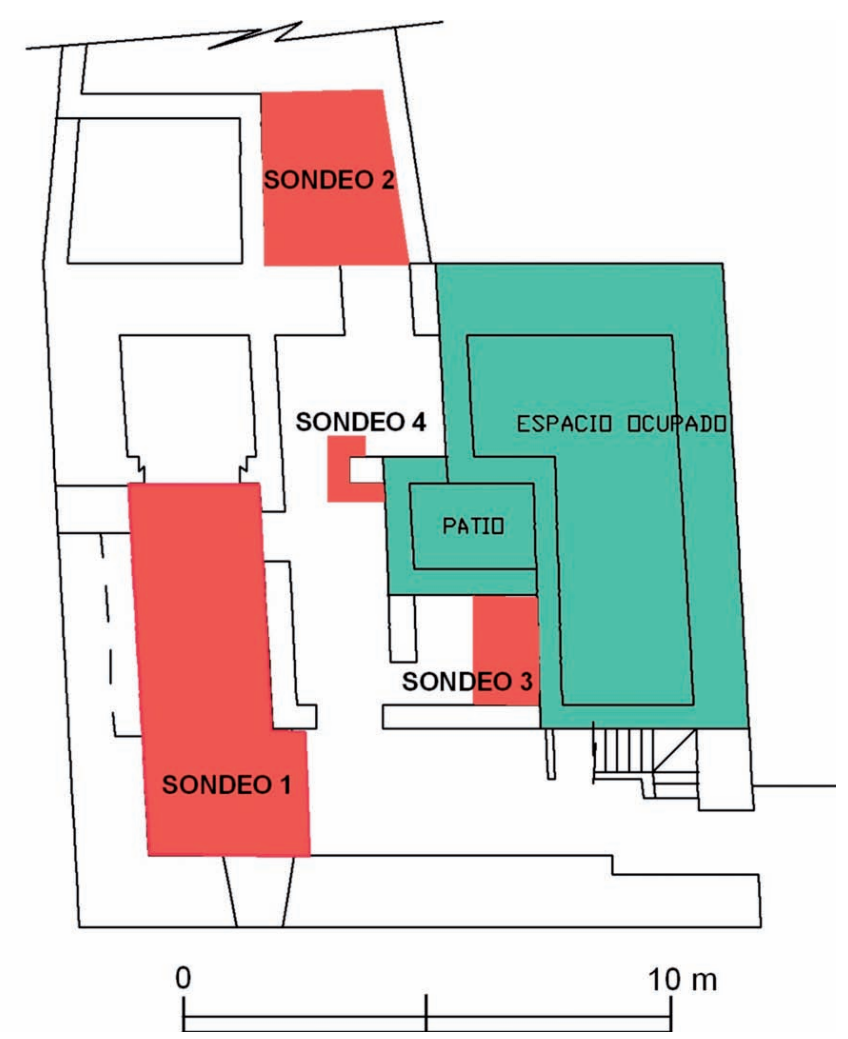

Fig. 7. Localización de los sondeos arqueológicos realizados (en rojo). También se delimita el espacio ocupado por la vivienda anexa, en el que no se ha podido intervenir (en verde). Planimetría base: Prudencio Martínez Medina
En cuanto a la excavación arqueológica, se optó por intervenir en una serie de áreas susceptibles de aportar más información para conocer el origen y evolución del edificio (Fig. 7). En el interior de la torre, los tres sondeos realizados nos han permitido documentar al interior la cimentación de los muros perimetrales, los muros interiores originales que la compartimentaban, algunos sectores del pavimento original, así como, en general, las diversas reformas que ha ido sufriendo el edificio hasta la actualidad. En el sondeo realizado en el patio exterior pudimos documentar el exterior de la cimentación de los muros perimetrales y las estructuras correspondientes a habitaciones adosadas al torreón en época moderna o contemporánea.

\section{ANÁLISIS ARQUEOLÓGICO DE EL FUERTE DE LANTEIRA}

A la hora de exponer los resultados del análisis arqueológico de El Fuerte de Lanteira vamos a ofrecer de forma conjunta los datos procedentes del estudio de las estructuras emergentes y la información proporcionada por los sondeos realizados, dado que así podemos explicar mejor la evolución del edificio. En primer lugar, habría que insistir en el hecho de que al no poder actuar en una parte de esta antigua fortificación, por estar en posesión de otro propietario, el análisis se ve sujeto a limitaciones, aunque pensamos que los resultados nos permiten entender adecuadamente tanto la estructura original como las principales transformaciones.

El análisis lo vamos a organizar en función de nuestra hipótesis de evolución cronológica, por lo cual nos centraremos en describir la estructura original de la torre, su planta y técnicas constructivas, para puntualmente analizar las principales transformaciones que ha sufrido.

El Fuerte de Lanteira es un edificio de planta casi cuadrada, 14,05 metros de longitud N-S, medida tomada 
en la pared oeste y 14,25 metros de longitud E-O, medida tomada en la pared sur, es decir en los dos lados medibles externamente ${ }^{13}$, cuyo perímetro está formado por un grueso muro de técnica mixta de mampostería en la planta baja, con un grosor que oscila entre 1,50 y 1,55 metros, y tapial en la planta alta, cuyo grosor varía entre 1,10 y 1,15 metros, quedando un escalón en la unión entre las dos fábricas que sirve para el apoyo del primer forjado que cubre al interior la planta baja. La altura máxima conservada es de 6,25 metros en la esquina $\mathrm{SO}$, pero su altura original debió ser mayor, dado que en algún momento, cuando perdió su función defensiva, debió de ser desmochado. Al documentar por lo menos tres cajones de tapial, y considerando la altura de los cajones que se han conservado por entero, podemos argumentar que como mínimo el edificio debía medir en la esquina SO 6,60 metros, estando constituida al menos por una planta baja y un piso superior. Si la comparamos con las alturas conservadas en las torres de alquería del territorio granadino, es muy probable que tuviera un número mayor de plantas, desarrollando una mayor altura ${ }^{14}$. El gran tamaño de su base, además, es indicativo también de la posibilidad de que esta torre fuese aún mayor.

En el interior de la torre, los sondeos realizados nos han permitido documentar los muros de carga originales que la compartimentaban. Son muros de mampostería de 0,60 metros de anchura media en su base que dan lugar a la formación de tres estancias o habitaciones en forma de «U», organizadas en torno a un patio interior (Fig. 8). Estos muros, junto a los perimetrales, soportan el mencionado primer forjado de la torre. Es probable que, como en el muro perimetral, el alzado de estos muros en la planta alta fuese de tapial.

Respecto al pavimento original de la torre, solo se ha documentado con claridad en la zona identificada como patio interior y consistía en un suelo de tierra roja apisonada, bajo el cual encontramos un relleno de nivelación de piedras de gran tamaño y tierra gris que se apoya sobre el nivel de roca (conglomerado). En el resto de la edificación no se han identificado estratos que podamos asociar a niveles de suelo originales, ya que la propia construcción marca un límite de rigidez en el techo de la primera planta que no permite alzar mucho la cota del

${ }_{13}$ Debemos señalar que las medidas realizadas varían según donde se tomen, debido a la irregularidad del aparejo de mampostería compuesto por lajas de micaesquistos. En la primera publicación que catalogó el edificio se daban como medidas 14,10 m × 14,40 m (Martín García Mariano; Bleda Portero Jesús y Martín Civantos José María, Inventario de Arquitectura Militar de la Provincia de Granada (Siglos VIII al XVIII), Granada, 1999, pp. 287-289).

${ }^{14}$ Mariano Martín García: «Torres de alquería...», p. 663.

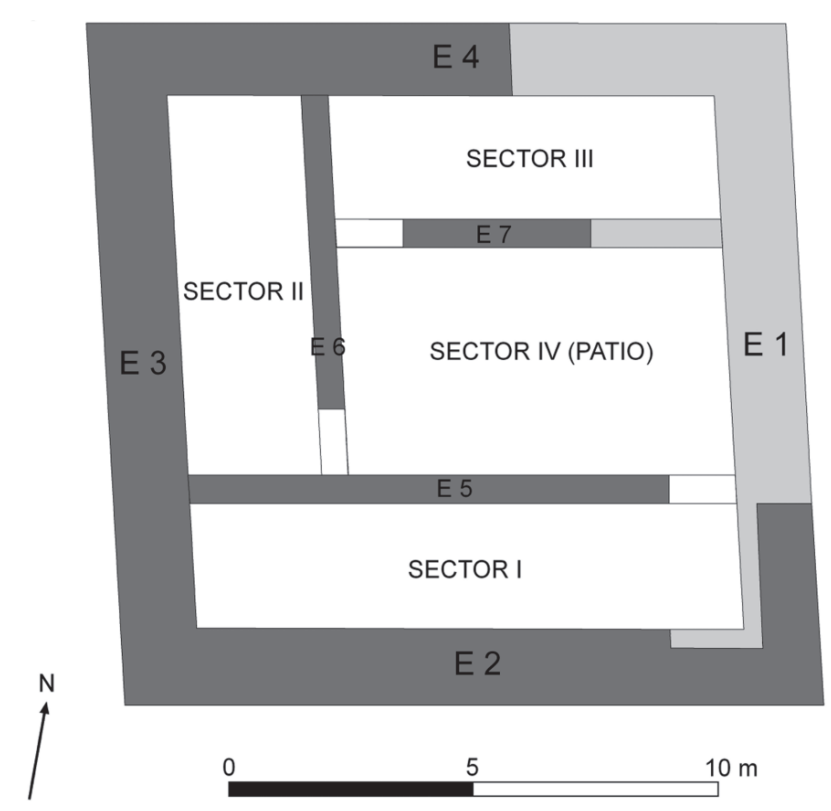

Fig. 8. Planta original de El Fuerte de Lanteira (hipótesis). En gris oscuro los muros documentados en la parte propiedad del Ayuntamiento y en gris claro el trazado hipotético, que queda dentro de la vivienda colindante.

suelo en la planta inferior. Eso ha provocado en varias ocasiones que las reformas en la fortificación hayan supuesto el rebaje de los suelos y no su colmatación con rellenos, lo que explica la escasa potencia arqueológica documentada en gran parte de las zonas excavadas y la ausencia de suelos originales, aunque en algún caso si se han conservado restos de los rellenos originales de nivelación. El escaso material recuperado en estos rellenos nos permite datar la construcción en época nazarí (siglos XIV o $\mathrm{XV}$ ), pero es insuficiente para precisar más. Lo que si observamos es que este espacio no estaba ocupado anteriormente por ninguna otra edificación.

En cuanto a los forjados, encontramos en la actualidad dos sistemas diferentes de cubrir las estancias de la planta baja, pero no tenemos la seguridad respecto a los que pudiera disponer la estructura original.

Una vez realizada esta descripción general de la estructura, vamos a detallar las características específicas de cada elemento.

\subsection{Muros perimetrales}

Como hemos comentado, los muros perimetrales de El Fuerte de Lanteira están realizados en mampostería y tapial, por lo cual desde un primer momento en nuestro análisis hemos sido muy minuciosos al valorar si esta diversidad responde a varias fases constructivas, siendo el resultado de reparaciones, o bien responde a un solo momento constructivo. En su descripción hay que tener en 
cuenta la denominación que hemos dado a sus distintos tramos: estructura 1 (E1) a la cara E, estructura 2 (E2) a la cara $S$, estructura 3 (E3) a la cara $\mathrm{O}$ y estructura 4 (E4) a la cara N. Por otra parte, vamos a proceder a la descripción de abajo hacia arriba, partiendo de la cimentación.

La cimentación la hemos documentado al interior del edificio en el sondeo $1 \mathrm{y}$ al exterior en el sondeo 2. De la información proporcionada llegamos a la conclusión que se excavó en la roca una zanja con el objetivo de crear una cimentación de mampostería de lajas de micaesquistos ${ }^{15}$ ligeramente en talud al exterior y con una zarpa de unos 0,40 metros de anchura media al interior. No hemos documentado la altura total de esta cimentación, aunque en la esquina suroeste, donde se ha rebajado el terreno al exterior de la torre, calculamos que es al menos de 0,70 metros.

Sobre esta cimentación se levanta un primer alzado de mampostería, también de lajas de micaesquistos (con cierta presencia de cuarcitas), en el que no se observan evidencias de mechinales, presentando en las esquinas lajas de mayor tamaño ${ }^{16}$. Esta técnica constructiva la vamos a denominar Mampostería I (Fig. 9). Su grosor se sitúa entre 1,50 y 1,55 metros y su altura media es de 2,00 metros.

A continuación este aparejo cambia de forma uniforme en todo el perímetro a una mampostería concertada, con hiladas de grandes bloques de cuarcita encintadas por lajas de micaesquistos, observándose en las esquinas lajas de mayor altura y longitud a modo de sillarejos. Denominaremos Mampostería II a esta técnica ${ }^{17}$ (Fig. 10). Este alzado mantiene en principio el mismo grosor que el inferior, destacando la presencia de unos huecos circulares (mechinales) en la zona de contacto entre las dos técnicas de mampostería, tal vez para montar un andamiaje. Es algo que sólo se observa al exterior de la construcción, quedando al interior ocultos estos huecos, de haberlos, por las sucesivas capas de enlucidos y morteros de tierra, así como por reparaciones con pequeños y medianos mampuestos. La altura aproximada de este aparejo es de 0,80 metros.

Por encima de esta fábrica distinguimos otra realizada con la misma técnica (Mampostería II) pero con la

\footnotetext{
${ }^{15}$ La zona montañosa de Sierra Nevada, a cuyos pies se sitúa el pueblo de Lanteira, pertenece al complejo nevado-filábride, dominando una formación de micaesquistos grafitosos, lo que les da una tonalidad oscura, entre los cuales se intercalan lentejones de cuarcitas (Instituto Geológico y Minero, Mapa geológico de España 1:50.000. Guadix, Madrid, 1980, pp. 5-6). Son precisamente estos materiales (micaesquistos y cuarcitas) los que se utilizan en la construcción, aunque muchos de ellos están rodados, por lo que deben proceder de materiales recuperados en el lecho de los ríos.

${ }^{16}$ Unidades estratigráficas (UE/S) 10140 (E1), 10240 (E2), 10340 (E3) y 10440 (E4).

${ }^{17}$ UE/S 10130 (E1), 10230 (E2), 10330 (E3) y 10430 (E4)
}

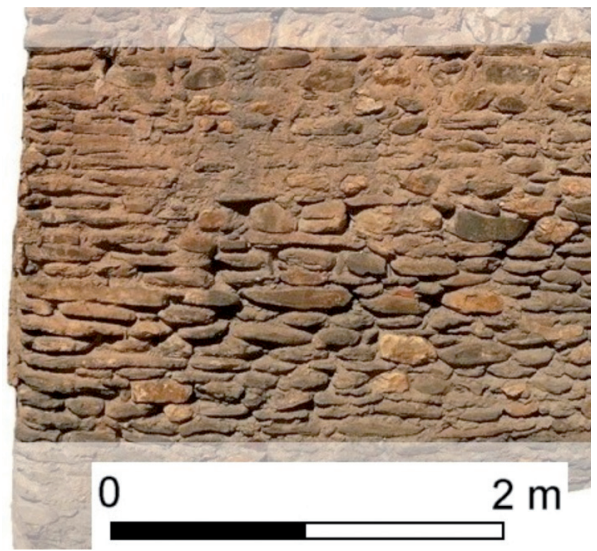

Fig. 9. Mampostería I (detalle)

peculiaridad de que es menos ancha, manteniendo al exterior la misma línea que los alzados inferiores (por lo que no se aprecia en esta zona el cambio), pero dejando un escalón al interior de 0,35 a 0,40 metros de ancho ${ }^{18}$. Además, el remate de esta fábrica está formado por una hilera de mechinales, que corresponden al inicio de la fábrica de tapial situada por encima. Aparte de la función de este escalón en relación con permitir el apoyo del forjado que cubre la primera planta, esta reducción de anchura se explica también por la necesidad de que los tableros para la construcción del tapial, que tiene una anchura media de 1,10 a 1,15 metros, se ajusten desde la base a esta mampostería. La altura media de este segundo nivel de la mampostería II es de 0,35 metros.

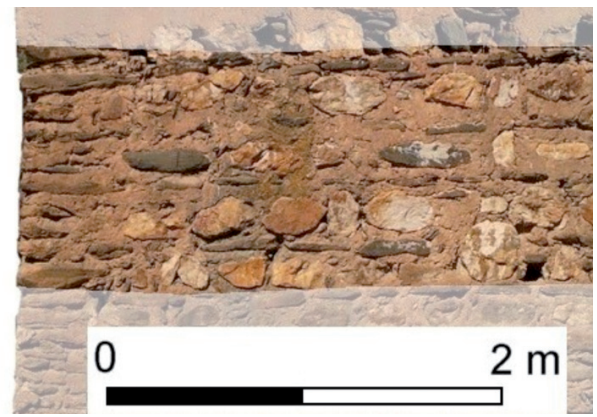

Fig. 10. Mampostería II (detalle)

Justo por encima de este último alzado de mampostería, encontramos una fábrica de tapial calicastrado con refuerzo de mampuesto en algunos puntos (sobre los mechinales y a lo largo de las huellas verticales dejadas en la superficie por los travesaños de los tableros) ${ }^{19}$ (Fig. 11). Este tapial, del que se han llegado a conservar hasta tres

\footnotetext{
${ }^{18}$ UE/S 10120 (E1), 10220 (E2), 10320 (E3) у 10420 (E4).
}

${ }^{19} \mathrm{UE} / \mathrm{S} 10110$ (E1), 10210 (E2), 10310 (E3) y 10410 (E4). 


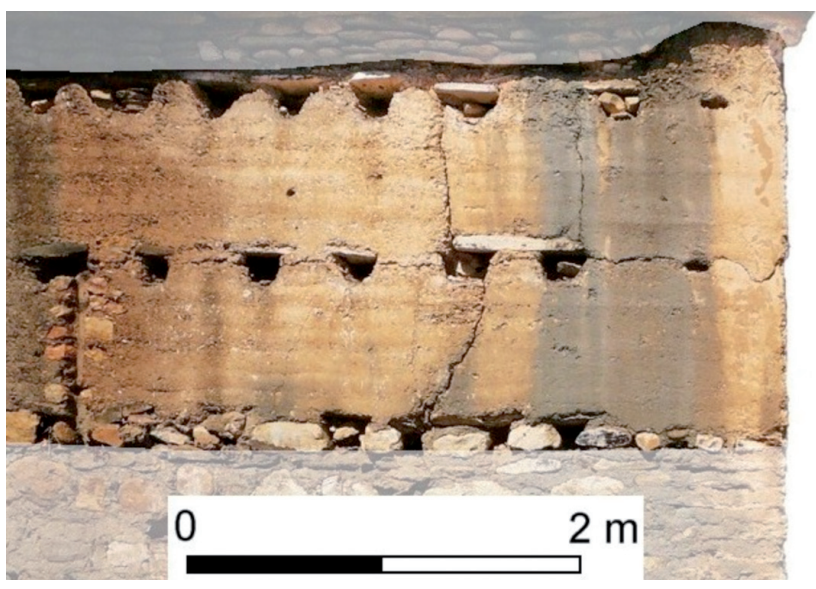

Fig. 11. Tapial (detalle)

cajones de altura, está muy deteriorado al exterior por las inclemencias del tiempo, pero ha podido ser estudiado con detenimiento al interior de la torre (totalmente en la E2 y parcialmente en las E1 y E3), donde se encuentra más protegido, aparte de haber recibido varios encalados, que, una vez retirados, han permitido observar las huellas que nos permiten conocer el proceso de construcción.

El tapial es, como hemos mencionado, del tipo denominado calicastrado, también llamado de cal y costra, caracterizado por presentar un material muy rico en cal en las caras exteriores, así como entre las tongadas con las que se va rellenando cada cajón, si bien en este caso se observa la presencia de abundante cal en forma de cuña, más ancha hacia las caras del tapial y que desaparece en el centro. Además de la cal, el tapial está compuesto por arcillas grises y pequeñas piedras de micaesquistos.

La altura más habitual de los cajones de tapial oscila entre 0,80 y 0,85 metros, si bien su longitud es muy variable, entre 1,65 y 2,60 metros, aunque la medida más habitual se sitúa en torno a 2,20 metros. Los tableros, o puertas de tapiar, utilizados suelen estar compuestos por cuatro tablas, cuya altura puede oscilar entre 0,15 y 0,25 metros, unidas por dos travesaños (que miden entre 0,05 y 0,08 metros de anchura), normalmente colocados en caras opuestas del tablero, de modo que por cada cara suele ser visible el travesaño a un lado y al otro las cabezas de los clavos que unen dichas tablas con el travesaño situado en la otra cara. Cada tabla ha sido unida al travesaño con dos o tres clavos, según su altura, por lo que suele ser visible en el tapial la impronta de entre 7 y 10 clavos en cada cajón, dispuestos verticalmente, en paralelo al lado menor del cajón. La cabeza de los clavos tiene un diámetro medio de 4 centímetros. No obstante, se observa una diferencia en la ejecución de la primera línea de tapiales, donde las marcas de los travesaños son visibles tanto al interior como al exterior, mientras que en la segunda línea sólo son visibles al interior, lo que indica un cambio en la forma de unión de los tableros exteriores (donde se evita que los travesaños queden marcados en el tapial, por lo que quedarían siempre al exterior de la puerta de tapiar, quedando solamente marcas de clavos en el tapial).

Se ha podido documentar, en la primera línea de tapiales, que su construcción se haría continua, es decir colocando varios tableros consecutivamente, no de uno en uno, y vertiendo después del material dentro de ellos. En concreto se ha documentado al interior del torreón una sucesión continua de cinco cajones de tapial en E2 y E3, abarcando la esquina de unión de ambos muros, de modo que esta zona está más cohesionada. Sólo el último de los tableros llevaría el cabecero, sujeto por los travesaños interiores, para cerrar el lateral y contener el material que se vertía dentro de los cajones; por ello en este último cajón no ha quedado la marca de dichos travesaños. Además se observa que la unión entre los tableros que se hacen de forma continua coincide con un mechinal en la parte de abajo, de modo que los costales se utilizan también para
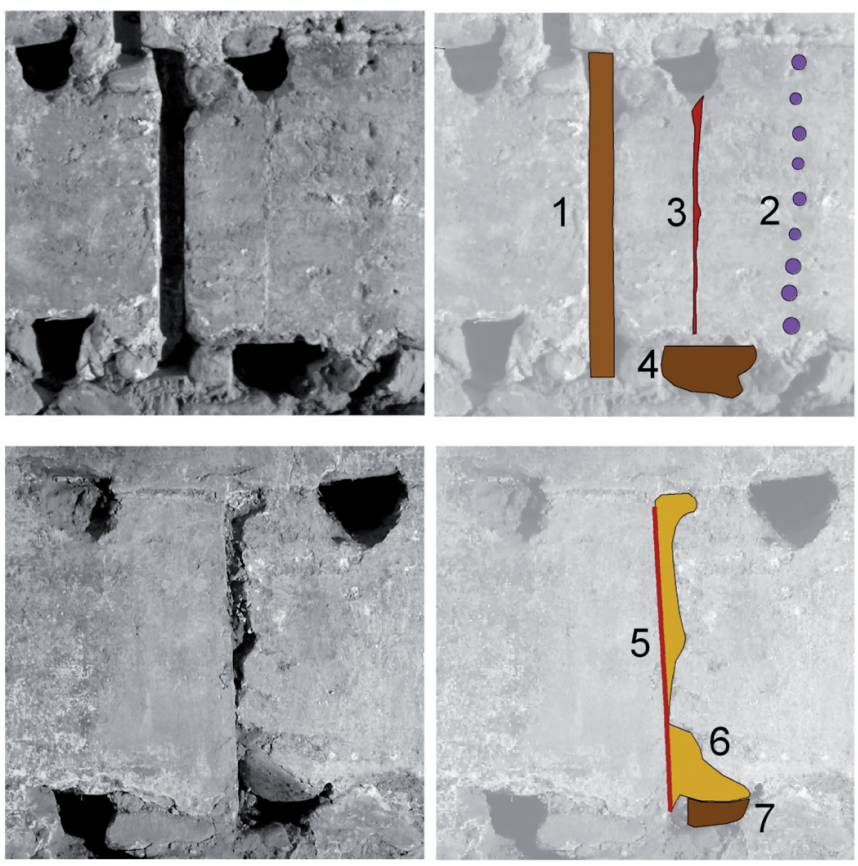

Fig. 12. Tipos de unión de los cajones de tapial (fotografía y esquema). En la parte superior, unión continua: 1: marca del travesaño que une las tablas de una de las puertas de tapiar; 2: marca de los clavos del travesaño del otro tablero; 3 : resalte o rebaba que queda en la zona de unión de las dos puertas de tapiar; 4: mechinal cuya aguja soportaría el costal que asegura la unión correcta de los dos tableros consecutivos. En la parte inferior, unión discontinua: 5: línea recta causada por el cabecero que determina el final de una sucesión de cajones; 6: irregularidades tras el relleno de una nueva sucesión de cajones que se apoya en la anterior; 7: el mechinal no se sitúa en la zona de unión, sino al comienzo del nuevo cajón 


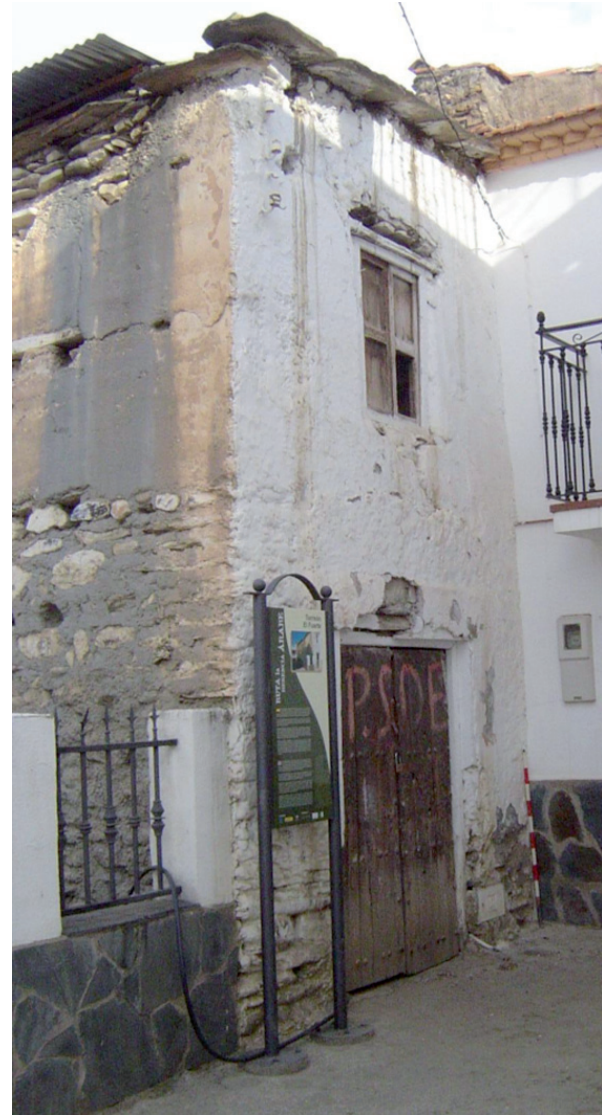

Fig. 13. Vista del muro perimetral este (E1). Pueden observarse algunas de las modificaciones sufridas a lo largo del tiempo (reducción de altura y colocación de nueva techumbre; apertura de puerta y ventana; adosamiento de otra vivienda; etc.)

afianzar la unión entre las puertas de tapiar de cada uno de los cajones. Esta característica se ha podido documentar al interior, por el buen estado de conservación del tapial, que estaba cubierto (y protegido) por sucesivos encalados (Fig. 12).

Hay que observar, por otra parte, que entre las líneas de cajones de tapial documentamos los mechinales, huecos donde se insertan las maderas, denominadas agujas, que se utilizan para armar los tableros. Sus dimensiones son variables y su forma irregular, aunque normalmente miden en torno a 0,14 $\times 0,14$ metros. En algún caso se conserva todavía la madera dentro del mechinal. Una característica de estos mechinales es que están reforzados con lajas planas de pizarra en la parte superior. Según se ha podido observar, estos huecos o mechinales se abrirían en el tapial a modo de roza, una vez concluida cada hilera. Son muy numerosos, siendo la distancia habitual entre ellos de 0,40 a 0,50 metros.

Los muros de tapial fueron arrasados a la altura de la tercera línea de cajones de tapial, que sólo es visible en la parte inferior, de modo que la altura máxima conservada del aparejo de tapial es de 2,40 metros en la muralla perimetral oeste (E3).

A pesar de la existencia de tres fábricas distintas (mamposterías I y II y tapial I), que en un primer lugar nos llevó a plantear la posibilidad de que la torre hubiese sufrido transformaciones en distintos momentos, no se evidencia ningún tipo de línea de ruptura, sino un cambio homogéneo a una misma altura, por lo que deducimos que estos muros corresponden a una única fase constructiva.

Las principales transformaciones que han sufrido estos muros perimetrales han sido su arrasamiento a un determinado nivel para reducir su altura, la apertura de vanos (puertas y ventanas), la reducción de su grosor al interior para aprovechar más el espacio, así como el adosamiento de otros edificios al exterior (Fig. 13). Todas estas transformaciones están relacionadas con la pérdida de su funcionalidad como fortificación a partir del siglo XVI y su transformación en un edificio cuyo uso ha sido diverso a lo largo del tiempo (vivienda, sede de una agrupación socialista, horno de pan, cuadra, etc.) y además no ha sido homogéneo, dado que ha sido habitual la fragmentación del edificio en unidades, familiares o colectivas, diferenciadas.

\subsection{Muros interiores}

Uno de los procesos más interesantes de la intervención arqueológica ha sido investigar la estructura interior de la fortificación, obteniendo resultados muy satisfactorios y algo sorprendentes, pues el torreón no constituía una estructura totalmente cubierta, sino que muy probablemente disponía de un patio interior. En tres de los sondeos realizados (sondeos 1, 3 y 4 ) se ha podido documentar la cimentación de los muros interiores, lo que ha permitido discriminar cuáles son contemporáneos a la construcción del edifico, de aquellos que responden a particiones posteriores del espacio. En concreto, se han documentado tres muros interiores que consideramos contemporáneos a la primera fase constructiva de la fortaleza, que se han denominado E5, E6 y E7.

Estos muros presentan unas características similares. Disponen de una pequeña zanja de cimentación, en la que se colocan las primeras hiladas de mampuestos, normalmente micaesquistos de ángulos redondeados, con una anchura de 0,55 a 0,60 metros. El alzado de estos muros se haría en mampostería en la planta baja ${ }^{20}$, siendo probablemente de tapial de tierra en la planta alta, como aún se documenta en el muro E6.

${ }^{20}$ UE/S 10501 (E5), 10513 (E6) y 10528 (E7). 


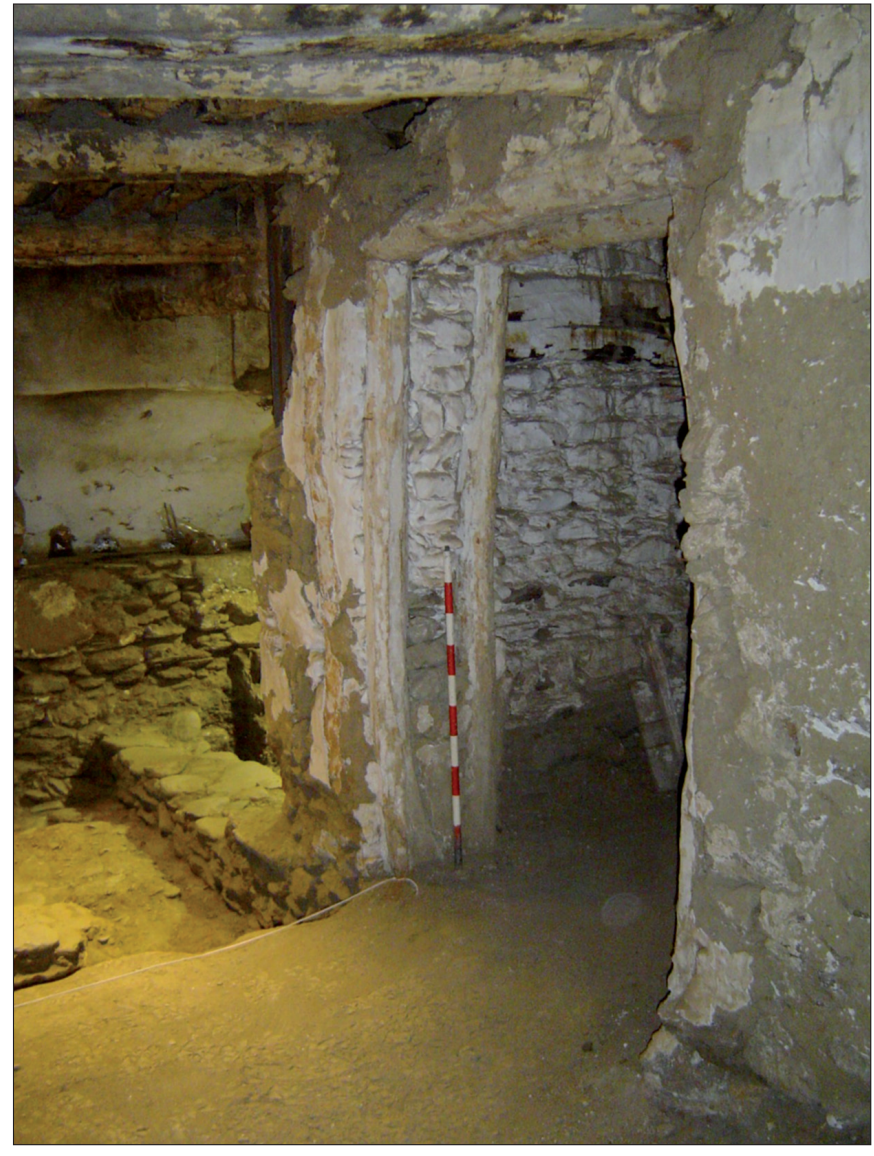

Fig. 14. Muro interior E5: documentación de la cimentación en el sondeo 1 en contacto con el muro perimetral E3, a la izquierda, y vano actual de comunicación, no original, a la derecha (vista desde el sector I)

El primero en ser construido (E5) es paralelo a la muralla que da a la cara $S$ de la fortaleza (E2), apoyándose en E1 y E3 (Fig. 14). Ello da lugar a una estancia con unas medidas aproximadas de 2,65 × 11,30 metros, que hemos denominado sector I. Este muro dispone de una puerta o vano, probablemente original (UE 10502), con dintel de vigas de madera, que se apoyan directamente en la muralla E1 (Fig. 15). Este vano, actualmente cegado, daría acceso a una estancia situada al $\mathrm{N}$, probablemente un patio interior (sector IV).

El segundo muro en ser levantado (E6) se dispone en paralelo a la muralla situada al $\mathrm{O}$ del edificio (E3), apoyándose en E4 y E5. Así se crea una estancia con una medidas aproximadas de 2,65 × 7,80 metros, que hemos denominado sector II. Este muro disponía también de un vano, que creemos que es original (UE 10514), con dintel de vigas de madera, que, como en el caso anterior, serviría para acceder al patio (sector IV) (Fig. 16). Estas vigas se apoyan directamente en el muro E5. En la actualidad este vano está cegado. La peculiaridad de este muro es que en la

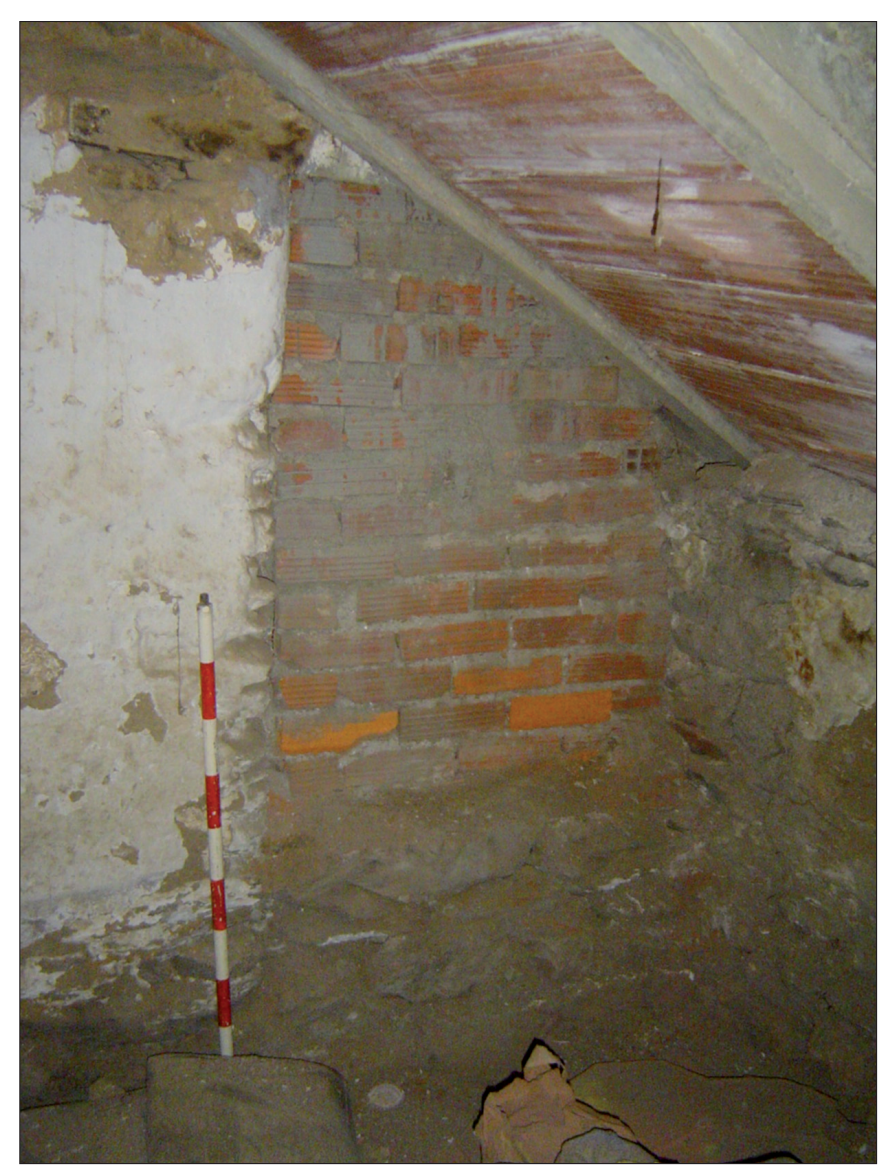

Fig. 15. Acceso original al patio interior en el muro interior E5 (UE 10502), amortizado por las obras de la escalera actual de acceso a la segunda planta (vista desde el sector I)

planta alta conserva un alzado de tapial de tierra (UE 10522), que probablemente corresponda a la estructura original del torreón (Fig. 17).

El tercer muro en ser levantado (E7) se sitúa en paralelo a la muralla situada al $\mathrm{N}$ de la fortaleza (E4), apoyándose probablemente en E1 (circunstancia que no se ha podido verificar por situarse este contacto en la propiedad del vecino) y con seguridad en E6. De este modo encontramos una estancia con unas medidas aproximadas de 2,65 x 8,10 metros, que hemos denominado sector III. Como en los casos anteriores, encontramos un vano (UE 10529), todavía abierto, también con dintel de vigas de madera, que se apoyan en el muro E6 (Fig. 18). Igual que los otros, este vano serviría para comunicar el sector III con el patio interior o sector IV.

Para ninguna de las estancias que hemos comentado, correspondientes a los denominados sectores I, II y III, se ha documentado el posible pavimento original, si bien en el caso de la estancia del sector II se ha observado que dicho pavimento se situaría sobre un relleno de arcillas 


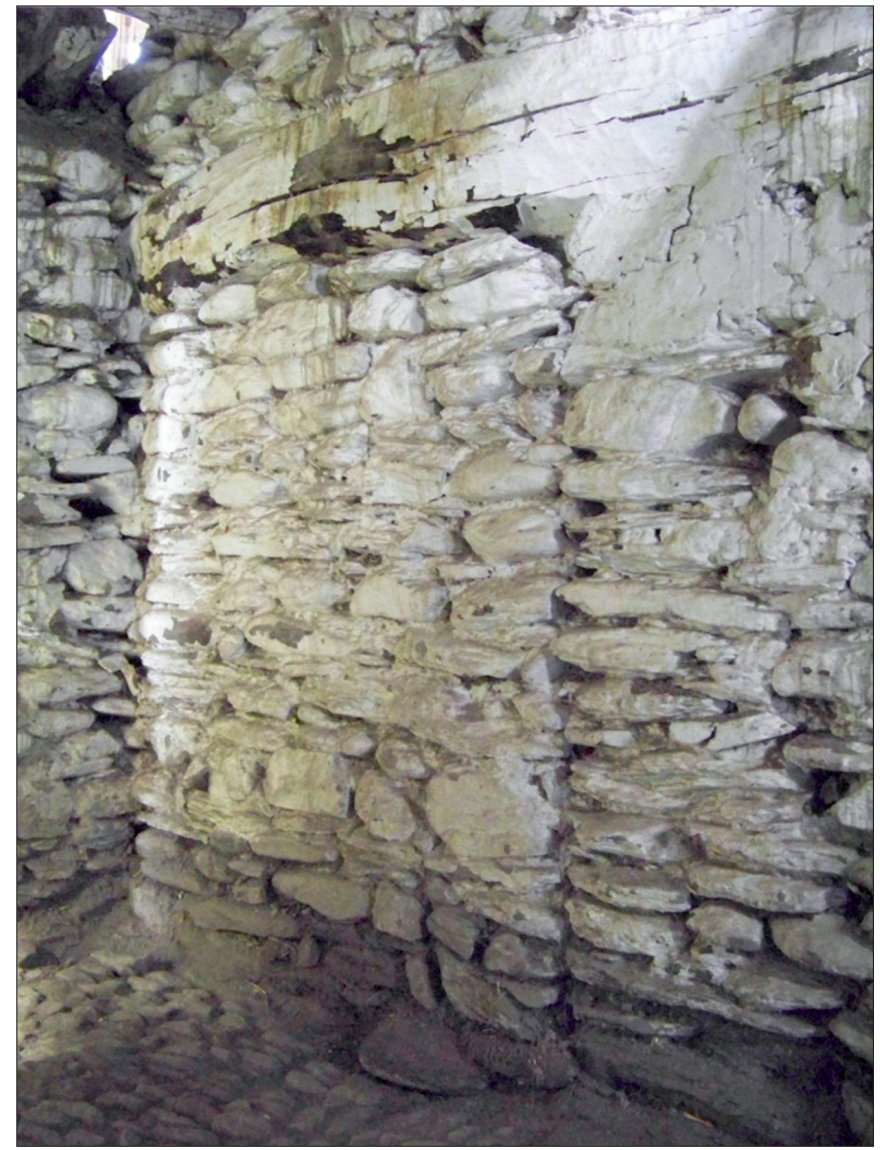

Fig. 16. Acceso original hacia el patio interior en el muro interior E6 (UE 10514), actualmente cegado (vista desde el sector IV)

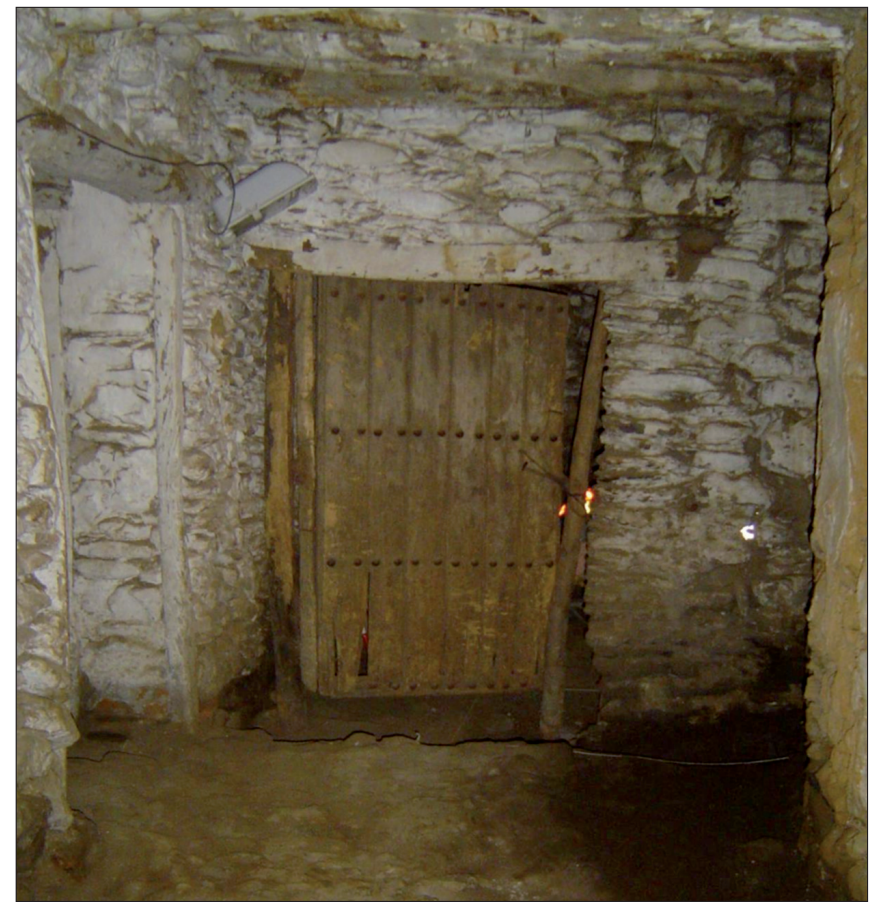

Fig. 18. Muro interior E7, vista del vano, probablemente original, de comunicación con el patio interior (UE 10529). Es el único de los tres vanos que consideramos originales que no ha sido tapiado y aún sigue utilizándose (vista desde el sector IV)

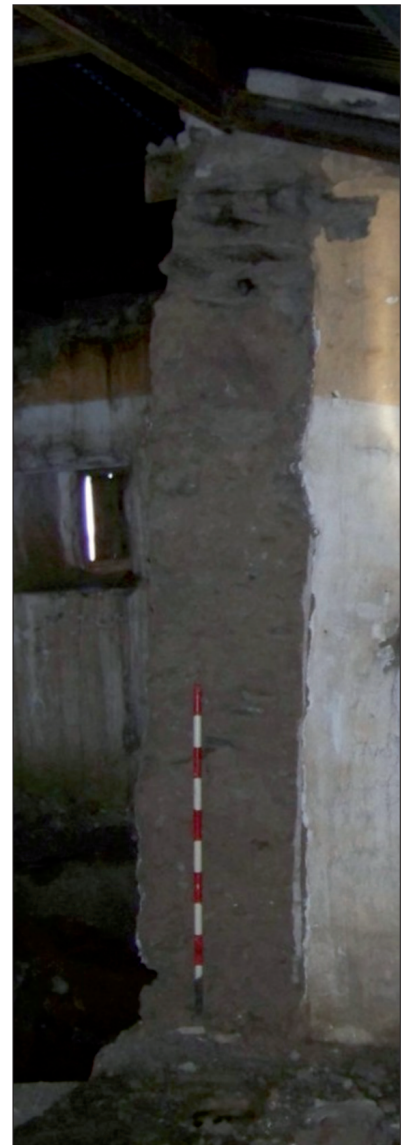

Fig. 17. Perfil del muro E6 en la zona superior, donde está fabricado con un tapial de tierra, con poca o ninguna cal (UE 10522) (vista desde la planta alta del sector IV)

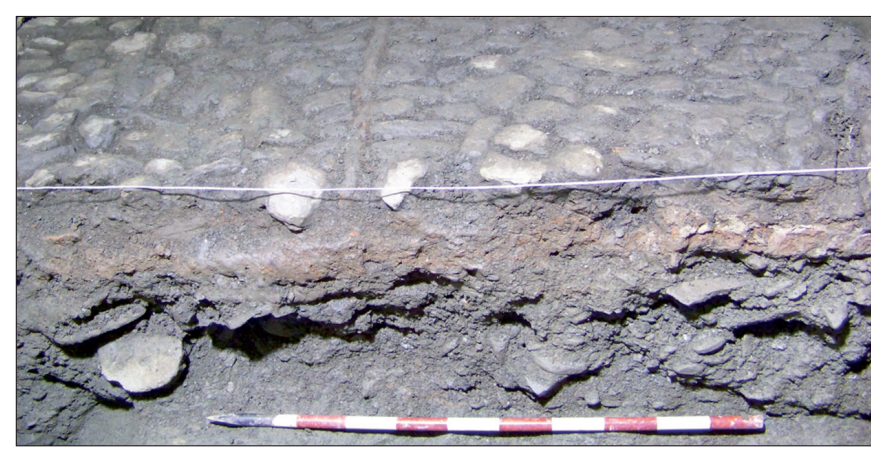

Fig. 19. Perfil oeste del sondeo 3, donde puede observarse, bajo el empedrado moderno (UE 3001), una capa de tierra rojiza correspondiente al pavimento del patio original (UE 3007), situada sobre un relleno de piedras y tierra gris (UE 3008)

grises y piedras (micaesquistos), en ocasiones de mediano a gran tamaño, el cual nivela los estratos de roca.

Estos tres muros (E5, E6 y E7), junto al muro perimetral E1, delimitan un espacio que hemos denominado sector IV, que probablemente correspondía a un patio, con una dimensiones aproximadas de 4,60 x 9,65 metros. El pavimento de este patio es un nivel de arcilla roja 


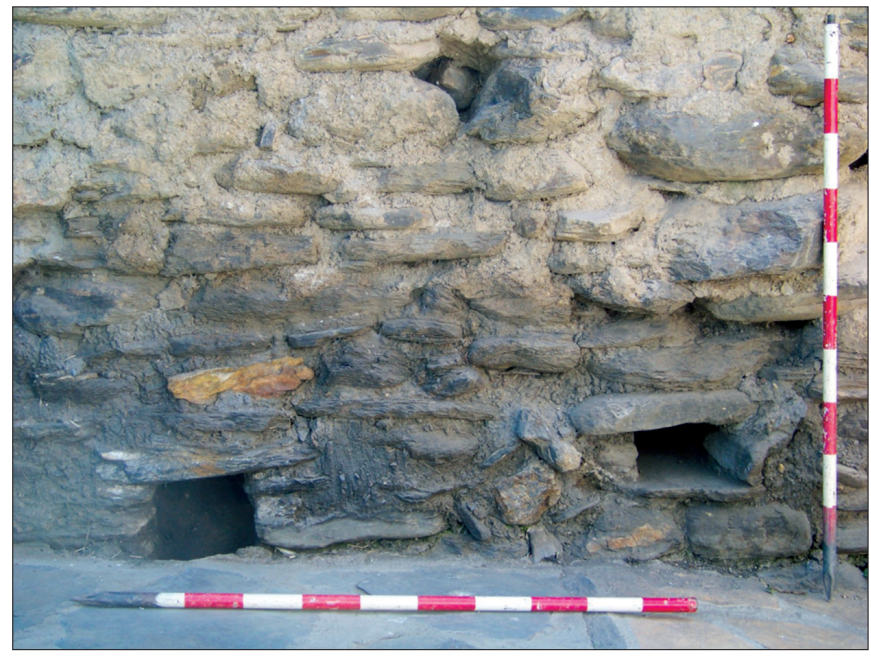

Fig. 20. Salida al exterior de dos canalizaciones existentes en la base del muro perimetral oeste E3 (UE/S 10347 y 10348)

compacta que se sitúa por encima de un relleno de nivelación hecho con arcillas grises y piedras de mediano a gran tamaño, normalmente micaesquistos (Fig. 19). Es muy probable que el acceso desde el exterior a esta fortificación se hiciese directamente a este patio, por lo que la apertura original tal vez se encontraría en el muro perimetral E1, pero no hemos podido verificar esta hipótesis al situarse casi todo este tramo de muro en la propiedad del vecino. Respecto al sistema de evacuación de agua del patio, hay que pensar que alguno, o ambos, de los dos huecos observados en el tramo de muralla E3 (UE/S 10347 y 10348) (Fig. 20), frente al vano ubicado en el muro E6, sirvieran para recoger las aguas a través de algún sistema de canalización que atravesara la estancia (sector II) y condujera las aguas hacia el río del Pueblo.

\subsection{Forjados}

Las estancias que consideramos originales tienen diferentes forjados que las cubren, de modo que no podemos estar seguros de la disposición original de los sistemas de cubiertas de la primera planta. El sector III, que sólo en parte ha podido ser analizado (la mitad de la primitiva estancia es propiedad del vecino), está cubierto con rollizos de madera que se apoyan en los muros E4 y E7, los cuales a su vez sirven de apoyo a las lajas de pizarra, conocidas con el nombre de aleros, sobre las cuales debe de situarse un relleno de tierra (launa) y luego el pavimento (Fig. 21), si bien en esta zona no hemos podido documentarlo, dado que la parte superior de esta estancia está incorporada a la vivienda del vecino. En cualquier caso, es probable que la cubierta original fuese de este tipo.

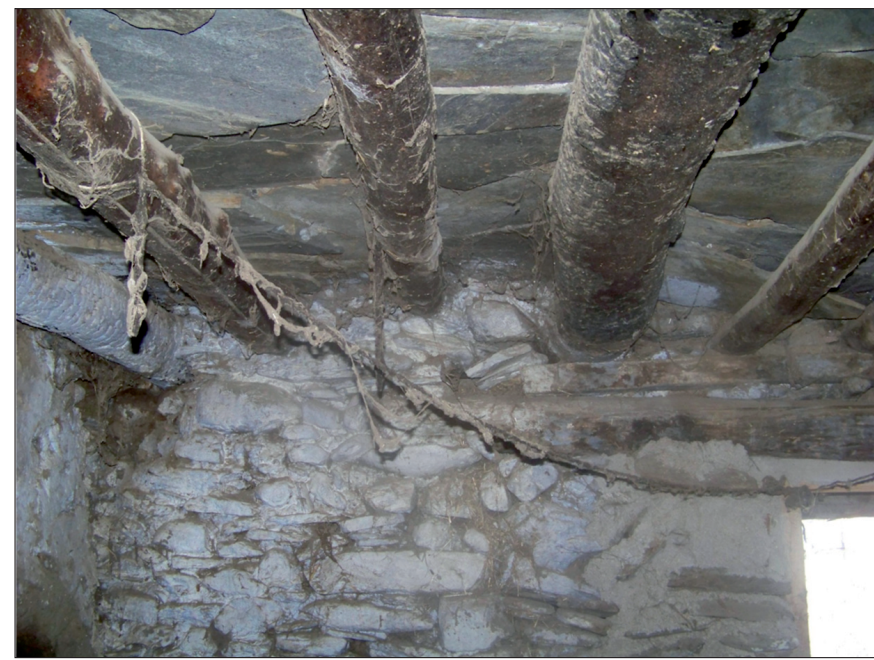

Fig. 21. Detalle de la cubierta del sector III

En cambio, la cubierta de los sectores I y II, casi con seguridad debida a una reforma relativamente reciente (siglo XIX o principios del XX), se organiza a partir de gruesas vigas de madera (castaño) que se apoyan en los muros (E2 y E5 en el sector I y E3 y E6 en el sector II), las cuales sirven de sustentación a otras vigas más pequeñas, dispuestas en perpendicular a las más grandes, sobre las cuales se disponen una primera capa de aleros de pizarras, que a su vez reciben otra capa de tierra (arcilla gris) que sirve para nivelar y sobre la que se dispone una solería de grandes lajas de pizarra de forma rectangular, bien trabajadas, pero de medidas diferentes, aunque encajando unas con otras (Fig. 22).

Por otra parte, las reformas posteriores nos impiden tener información sobre el primitivo sistema de acceso a la

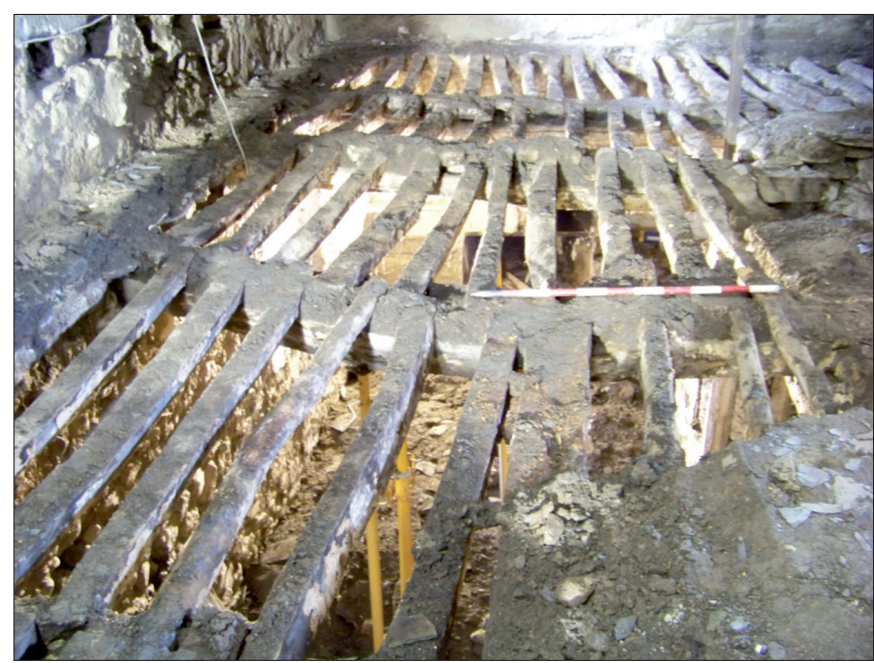

Fig. 22. Figura. Detalle de la cubierta de los sectores I y II 
planta alta, que tal vez se realizaba a través del patio interior.

\subsection{Períodos identificados en la construcción}

(Figs. 25-27)

Como ya hemos anunciado anteriormente, son varios los periodos que se han podido identificar durante la actividad arqueológica. Al cruzar esta información con la obtenida del examen de la documentación escrita y, sobre todo, de las fuentes orales de la gente del pueblo, hemos podido distinguir una periodización, que presentamos de manera resumida:

1.- Corresponde a la construcción original de la fortificación, con la fábrica de mampostería y el tapial original (UE/S 210, 220, 240, 310, 320, 340, 410, $420 \mathrm{y}$ 440). A esta fase corresponden también dos pequeños huecos de salidas de agua del muro oeste. Este primer momento se ha datado, como después explicaremos, en los siglos XIV-XV.

2.- En un segundo momento la construcción va a desmocharse, rebajándose su altura, y nivelando la parte superior de la construcción con mampostería. Todo ello quedaría cubierto con aleros de pizarra. En este mismo periodo se abriría una puerta en el muro este, lo que permitiría el acceso directo a la calle, así como también la mayor parte de las ventanas de los demás muros (aunque en algún caso tenemos dudas sobre la posibilidad de adscribir algunos de estos vanos al tercer período). La cronología de esta reforma la situamos entre los siglos XVIXVIII. Es el momento de conversión del edificio en un espacio no fortificado, probablemente con función doméstica (como se deduce de la pérdida de altura y la apertura de vanos), aunque resulte difícil saber si sería ocupada por una o por varias familias, o si alguno de sus espacios cumpliría otras funciones, como almacén o cuadra.

3.- Al siglo XIX y comienzos del $\mathrm{XX}$ podemos asignar una serie de reformas vinculadas a la construcción de una estancia en forma de L que abarca los sectores I y II, cuya cubierta de la planta baja es reforma$\mathrm{da}$, mientras que en la planta alta se dispone un enlosado muy cuidado. Además se reforma la puerta de acceso desde la calle en el muro este, para disponer junto a ella una escalera de subida a la planta alta. También se abre una puerta con remate en forma de falso arco en el muro norte, que da acceso a una habitación empedrada que se adosa al exterior del torreón y desde la cual se accede a un huerto. Por otra parte, es muy probable que en este momento se realice el empedrado del patio interior. Este período está asociado a la conversión del edificio en una vivienda más cuidada, dada la importancia y calidad de las mencionadas reformas.

4.- Posteriormente, en un momento que se puede situar entre los años cuarenta y sesenta del siglo $\mathrm{Xx}$, la puerta con falso arco en el muro norte sería cegada, habilitando con ello el espacio para la construcción de un horno de pan. Fue necesario, entonces, abrir otra puerta en el muro norte para acceder a la zona del huerto. Probablemente también a esta época corresponden las estructuras que se adosan a los muros sur y oeste, que han dejado su impronta en las huellas y huecos de vigas y enlucidos de cemento bastante modernos, en ocasiones con restos de ladrillos huecos, dando lugar a habitaciones anexas o a espacios que funcionarían a modo de porche. Tal vez en este momento una de las ventanas del muro sur sería cegada.

5.- Las últimas reformas que se detectan en la construcción, que pueden datarse en los últimos cuarenta años, corresponden a la construcción de una ruda chimenea en el muro este, así como todas las modificaciones ligadas a la construcción de la vivienda adosada en la parte norte y este de la construcción. Nos referimos al tejado de tejas curvas, que implicó un nuevo rebaje de la fábrica del tapial, entre otras. A este período corresponde también una fase, documentada solo al interior, en la que el espacio es compartimentado con tabiques de ladrillos, creando ambientes para usos diversos, fundamentalmente familiares. A partir de aquí, el deterioro de la construcción es progresivo, pudiendo documentarse en toda la torre distintas reformas toscas realizadas de manera apresurada. Con ello llegaría al estado en el que se encontraba en el momento de iniciar la intervención arqueológica.

\section{LA TORRE BAJOMEDIEVAL: CRONOLOGÍA Y PARALELOS}

Conocemos relativamente bien la estructura del torreón y sus técnicas constructivas, por lo que debemos pasar a plantear otra cuestión fundamental para poder analizarlo: la cronología de su fundación. Como punto de partida contamos con las reflexiones de J.M. Martín Civantos en su estudio sobre el Zenete medieval, que, aunque reconoce la dificultad de asignarle una cronología, cree que debe de ser una construcción que hay que fechar a partir del siglo XII, por su tipología, pero anterior a mediados del siglo XIV, por su técnica constructiva, al no estar construida totalmente con mampostería concertada en hiladas, como sí es el caso de las torres de la vega de Alcázar ${ }^{21}$.

\footnotetext{
${ }^{21}$ José María Martín Civantos: Poblamiento y territorio..., pp. 176 y 699.
} 
Nuestra intervención aporta nuevos argumentos, al contar con los restos cerámicos hallados en los rellenos para los pavimentos y en las fosas de fundación de los muros, pero también al haber tenido la oportunidad de realizar un análisis más riguroso de las técnicas constructivas.

Respecto al material cerámico, no obstante, nos hallamos con el problema de su escasa cantidad. Apenas si se han recuperado materiales y cuando se han hecho su principal característica es su alto grado de fragmentación. No obstante, algunas de las piezas nos permiten realizar consideraciones de interés, en especial dos fragmentos de cazuelas de una misma tipología, localizados en los rellenos de preparación para el pavimento en los sectores I (UE 1012) (Fig. 23) y IV (UE 3008), correspondientes a la primera fase constructiva de la fortificación. Se trata de un tipo de cazuela de borde recto y alero al exterior, muy características del mundo nazarí, que podemos fechar entre los siglos XIV y XV, por comparación con otros contextos ${ }^{22}$.

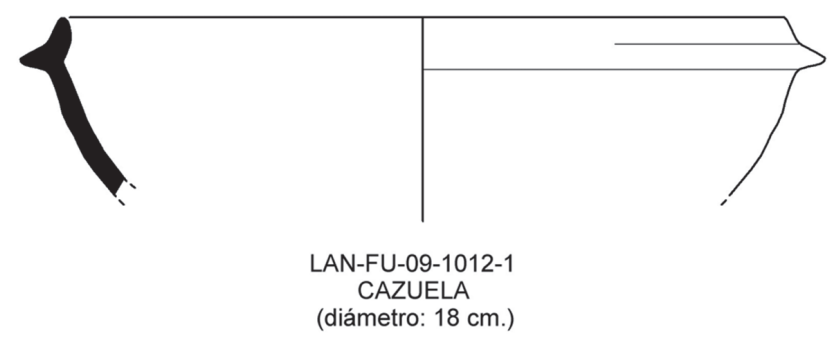

Fig. 23. Cazuela de época nazarí (siglos XIV-XV) documentada en niveles asociados a la construcción de la fortificación

Esta cronología debemos contrastarla con el estudio de la técnica constructiva. Como ya hemos comentado, a pesar de la existencia de tres fábricas distintas, detectamos un solo momento constructivo, si bien desconocemos el porqué de la utilización de las distintas técnicas, aunque veremos que no se trata del único ejemplar de fortificación que las presenta.

Si analizamos de forma independiente cada técnica constructiva, observamos que la mampostería I, es decir de lajas de micaesquistos, es la que ofrece menos posibilidades de datación, siendo incluso la técnica usada de for-

\footnotetext{
22 Antonio Malpica Cuello y Antonio Gómez Becerra: Una cala que llaman La Rijana. Arqueología y paisaje. Granada, 1991, pp. 88-90; ejemplares procedentes de Almería y Níjar, datados en el siglo XIV, en Isabel Flores Escobosa y María del Mar Muñoz Martín (coord.): Vivir en al-Andalus. Exposición de cerámica (s. IXXV), Almería, 1993, pp. 43-48. También es significativo que este tipo de cazuela prácticamente esté ausente en la cerámica de El Castillejo de Los Guájares (Granada), con una cronología principal entre fines del siglo XIII y principios del XIV, con sólo un ejemplar (entre 70) que se asemeja al nuestro (Alberto García Porras: La cerámica del poblado fortificado medieval de "El Castillejo» (Los Guájares, Granada), Granada, 2001, p. 515, núm. 61).
}

ma tradicional para la construcción de las viviendas del pueblo. Sin embargo, la mampostería II, formada por bloques de cuarzo, encintados por lajas de micaesquistos, es una técnica propia de las construcciones defensivas de los nazaríes, esencialmente a partir del siglo XIV, habiéndose propuesto incluso un programa constructivo de fortificaciones que llevaría a cabo el Estado nazarín . Así, por ejemplo, esta técnica de mampostería enripiada la encontramos en la vecina torre de Alcázar ${ }^{24}$, así como en torres de alquería del territorio de Loja, aunque en este caso con refuerzo de sillares de piedra caliza en las esquinas $^{25}$. En cuanto al tapial calicastrado, del tipo denominado por Graciani y Tabales como común o monolítico con remate de mampuestos sobre las agujas, estos autores datan su inicio en la zona sevillana en época almohade, estando también presente en momentos posteriores ${ }^{26}$.

A modo de conclusión sobre la cronología, la datación más probable del torreón de Lanteira nos lleva a los siglos XIV o XV, tanto basándonos en la escasa cerámica recuperada, como valorando la cronología que tradicionalmente viene asignándose a la mampostería enripiada, a pesar de ser una técnica usada solo puntualmente en el edificio.

Muy interesantes resultan también las comparaciones con otras fortificaciones medievales granadinas en las que además se documenta, sobre esa mampostería con refuerzo de sillares en las esquinas, una fábrica de tapial calicastrado, como es el caso de la torre más elevada del castillo de Lojuela en Murchas ${ }^{27}$ y la más interesante aún torre del tio Vayo, una fortificación de alquería, situada en Albuñuelas, en el valle del Lecrín ${ }^{28}$. Es este último caso el que creemos más susceptible de comparación con el de Lanteira, tanto por la posición de la construcción, en un extremo de la alquería — sobre un barranco-y en relación con la acequia que cruza por el interior del pueblo, como por su técnica constructiva, muy similar a la nuestra (aunque con variaciones que pueden explicarse

\footnotetext{
23 Manuel Acién Almansa: "Los tugur del reino de Granada. Ensayo de identificación", Castrum, 5, Archéologie des espaces agriares méditerranées au Moyen Âge, Murcia, 1999, pp. 427-438.

${ }^{24}$ José María Martín Civantos: "Alcázar, una alquería en la cara norte de Sierra Nevada (Granada)", Edad Media. Revista de historia, 6 (2003-2004), 225-255, en especial pp. 232-233.

${ }^{25}$ Miguel Jiménez Puertas: "Asentamientos rurales y frontera...», pp. 390-421.

${ }^{26}$ Amparo Graciani García y Miguel Ángel Tabales Rodríguez: «El tapial en el área sevillana. Avance cronotipológico estructural», Arqueología de la Arquitectura, 5 (2008), pp. 135-158, espec. p. 139.

${ }^{27}$ Antonio Malpica Cuello: Poblamiento y castillos..., p. 291.

${ }^{28}$ Antonio Malpica Cuello: Poblamiento y castillos..., p. 154. Otro caso que recuerda la construcción de El Fuerte de Lanteira es la Torre del Homenaje del castillo de Salobreña, dado que presenta un cuerpo inferior de mampostería y otro superior de tapial, pero en ambos casos encintados con ladrillo (Antonio Malpica Cuello: Poblamiento y castillos..., p. 321).
} 
por soluciones locales). No obstante es diferente a nivel tipológico, dadas sus menores dimensiones $(7,75 \times 6,45$ metros) y, por lo que conocemos hasta ahora, la ausencia de patio interior.

A este respecto, a nivel de tipología, la fortificación más parecida es la torre de Ferreira, también en el Zenete, organizada a partir de un patio interior, con estancias a su alrededor en forma de «L» (Fig. 24), aunque desconocemos si esta fue la disposición original. En este caso se trata también de una torre de planta cuadrada de grandes dimensiones, de 12 metros de lado, pero construida de forma uniforme de tapial, aunque con un zócalo de mampostería añadido como refuerzo ${ }^{29}$.

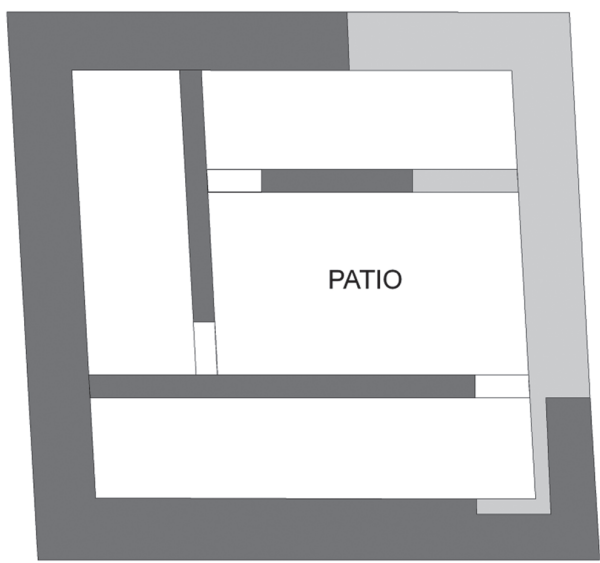

a

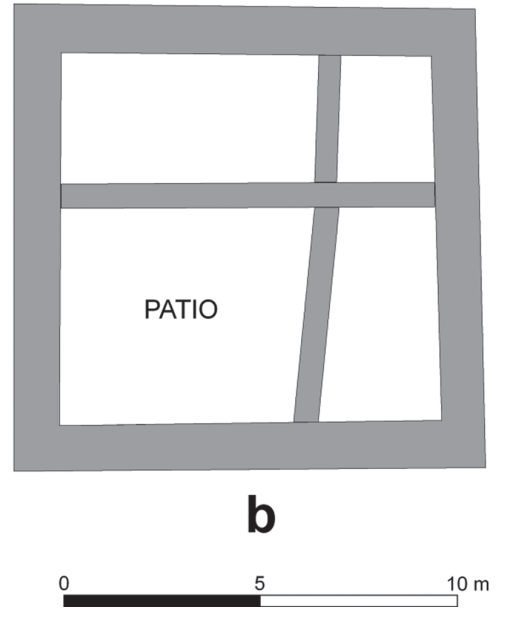

Fig. 24. Comparación entre las plantas de los torreones de Lanteira (a) y Ferreira (b) ${ }^{30}$

${ }^{29}$ José María Martín Civantos: Poblamiento y territorio..., pp. 120-121.

${ }^{30}$ La planimetría que se presenta de la torre de Ferreira, es una adaptación del plano publicado por José María Martín Civantos (Poblamiento y territorio..., CdRom), basado a su vez en el levantamiento efectuado por Antonio Martín Muñoz.

\section{LECTURA SOCIAL Y DEBATE HISTÓRICO SOBRE UNA TORRE DE ALQUERÍA DE ÉPOCA NAZARÍ}

En primer lugar, habría que comprender la función de estas torres para entender el motivo de su construcción y quiénes la promueven. Evidentemente, la primera respuesta, la más admitida y convincente, es la de su funcionalidad defensiva, ejerciendo un control del territorio - local y regional - mediante la vigilancia, semejante, por ello, a la de los castillos. Pero nosotros partimos de la idea de que hay una neta distinción entre los castillos rurales y las torres de alquería. Aquellos se ubican en cerros y su influencia se extiende sobre un amplio distrito en el que podemos encontrar varias alquerías y asentamientos dispersos. El papel del Estado, al menos a partir del siglo XI, es fundamental en la gestión de estos castillos, porque se trata de una forma de controlar el territorio. Esta función está en la conciencia colectiva de la población, como podemos ver en la siguiente referencia de Mármol de Carvajal a otro lugar situado en la cara sur de Sierra Nevada, en su relato de la rebelión de los moriscos: "Jubiles es el lugar principal de esta taa, donde se ven las ruinas de un castillo antiguo, en un sitio asaz grande y fuerte, en el cual dicen los Moriscos antiguos que habia en tiempo de moros un alcayde y gente de guerra para tener sujetos los lugares de aquel partido, que eran los mas inquietos de la Alpuxarra, barbaros y bestiales sobre manera»" ${ }^{31}$.

Frente a este modelo, Mármol de Carvajal también recoge referencias a las torres fuertes situadas en varias alquerías alpujarreñas, como en el caso de Huécija, en la taha de Marchena $^{32}$, o Albacete de Órgiva ${ }^{33}$. Introduciendo alimentos y agua en ellas, así como elementos susceptibles de

31 Luis del Mármol Carvajal: Historia del rebelion y castigo de los moriscos del reyno de Granada, Madrid, 1797, I, p. 274.

32 "Y luego mandó, que todos los Christianos se recogiesen con sus mugeres e hijos a una torre fuerte que habia en el lugar [...], y que metiesen agua y todo el bastimiento que pudiesen, por si fuese menester defenderse algunos dias en ella. Con esta orden se encerraron en la torre mas de docientas personas de los lugares de la taa; [...] No mucho después los Moros acordaron de poner fuego a la torre [...], llegaron a una esquina de la torre, y horadándola con picos, sin ser sentidos de los nuestros, ocuparon la boveda baxa, y metiendo en ella la madera de los retablos y de las imagines que habian deshecho, y mucha leña y tascos untados con aceyte revueltos en ella, le pusieron fuego. Por manera que quando los Christianos mal platicos y poco avisados sintieron el humo y la llama, ya el primer sobrado y la escalera de la torre ardía" (Luis del Mármol Carvajal: Historia del rebelion..., p. 326).

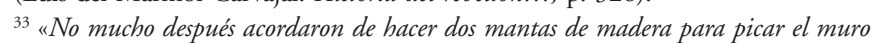
por debaxo, y dar con la torre en el suelo; mas los cercados se dieron tan buena maña, que les quemaron la una, teniéndola a medio hacer. La otra acabaron [...]. Esta manta era hecha de maderos gruesos, cubierta de tablas aforradas por defuera de cueros de baca, y sobre los cueros y la madera colchones de lana mojada, para que resistiesen las piedras y el fuego; y estando asentada sobre quatro ruedas baxas, los proprios que iban dentro de ella la llevaban rodando; y de un cabo y de otro iban arrastrando grandes haces de cañas, y de leña seca y tascos, untado todo con aceyte, para poner con ellos fuego a la torre, quando el muro estuviese picado y apuntalado con maderos. [...] Los nuestros procuraron deshacérsela, arrojando gruesas piedras sobre ella desde arriba; y viendo que no aprovechaba, porque la madera era recia, y los 
ser utilizados en su defensa (armas de fuego, pero también piedras, aceite, lino y cáñamo), era posible acoger a un número importante de personas, según las dimensiones de la torre, durante algunos días. El objetivo de los asaltantes es, casi siempre, aproximarse al pie de la torre para meterle fuego, introduciendo combustible en huecos abiertos en la zona inferior de la torre o, incluso, en la cámara baja (el acceso suele estar situado en alto), para forzar la rendición de los allí refugiados o incluso para derrocar la torre. Por su parte, el objetivo de los sitiados era impedir esta aproximación en espera de refuerzos llegados del exterior.

En realidad, esta función no es muy distinta a la de torres señoriales, como es el caso de las torres banderizas en el País Vasco ${ }^{34}$, del mismo modo que es significativo que en el reino de Granada fuese habitual que, tras la conquista castellana, permanecieran algunas de estas torres en lugares de señorío o incluso como residencia del señor o sus administradores. Un buen ejemplo puede ser el caso de la torre de Salar, a la que posteriormente se le adosó una casapalacio. A pesar de que los Reyes Católicos decretaron una general demolición de castillos y torres, salvo aquellas fortificaciones que interesaba seguir controlando, muchos señores consiguieron obviar esta orden, siendo de nuevo el caso de Salar, en manos de Hernán Pérez del Pulgar, uno de los más emblemáticos, pero no el único ${ }^{35}$.

Pero una cosa es que las torres puedan tener una función equivalente (proteger a unas personas refugiadas en su interior de otras que intentan atacarlas) y otra que su significado sea el mismo. Es decir, las torres señoriales son el medio, a veces sólo el símbolo, a través del cual se impone la autoridad, jurisdiccional o económica, sobre un territorio. En cambio, las torres rurales de época nazarí, aunque esporádicamente puedan servir para fines militares de control territorial, no tienen un papel similar a las señoriales, dado que no hay más jurisdicción que la de los sultanes y abarca todo el conjunto territorial del reino.

No obstante, no habría que descartar que algunos grandes propietarios construyeran torres en sus fincas, junto a las casas donde residían los arrendatarios, siguiendo

reparos, que llevaba encima, despedian la piedra, tomaron unos ladrillos mazaris, que acertó a haber en la torre, y arrojándolos de esquina donde se descubrían los colchones, rompieron el lienzo, y echando sobre ellos dos calderas de aceyte hirviendo [...], y cantidad de tascos de cáñamo y lino ardiendo, prendió el fuego de manera que en breve espacio se quemaron los colchones y la manta; y los que habian ya comenzado a picar el muro, se salieron huyendo con harto peligro de sus vidas" (Luis del Mármol Carvajal: Historia del rebelion..., pp. 339-340).

34 Agustín Azkarate Garai-Olaun e Ismael García Gómez: «Las casas-torre bajomedievales. Análisis sistémico de un proceso de reestructuración espacial/ territorial», Arqueología de la Arquitectura, 3 (2004), pp. 7-37, espec. pp. 20-29.

${ }^{35}$ Sobre la alquería de Salar, véase Miguel Jiménez Puertas: El poblamiento del territorio de Loja en la Edad Media, Granada, 2002, pp. 200-205. el modelo de los reyes nazaríes en sus propiedades situadas en el entorno del Soto de Roma, donde Muhammad II probablemente construyó varias torres, de las cuales aún se mantiene en pie la torre de Roma ${ }^{36}$. En esta línea, el ya citado cronista Mármol Carvajal alude a la ofensa que había sido para el morisco Miguel de Roxas suegro de Aben Umeya — proclamado rey de los moriscos-, el que las autoridades castellanas «no le habian dexado acabar una torre fuerte que hacia en su casa, antes se la había querido derriban ${ }^{37}$. Pero, en este caso, tal vez nos encontramos ante un intento de la élite morisca por emular a la castellana.

Sin embargo, los datos relativos a las fortificaciones de alquería del reino de Granada, parecen evidenciar que el modelo dominante no es aristocrático y que, en cambio, el papel de las comunidades rurales en la construcción de estas fortificaciones debió ser importante, aunque permanecen las dudas sobre el papel de los grupos de poder. ¿Qué peso tuvieron las élites locales en el control de estas fortificaciones? ¿De dónde proceden sus alcaides? ¿Cómo se vinculan con las ciudades, donde habitualmente residen los representantes del sultán?

En cualquier caso, la proliferación de estas torres y fortificaciones en alquerías e, incluso, como en Lanteira, en barrios, pone en evidencia que se trata de un fenómeno muy generalizado, mucho más que la posterior fortificación señorial en el reino de Granada tras la conquista castellana, debido, por una parte, al control de los Reyes Católicos sobre las fortificaciones, pero también al hecho de que es habitual que los señoríos, territoriales o jurisdiccionales, abarquen espacios más amplios que un barrio o alquería. Un caso significativo puede ser el del Marquesado del Zenete, donde se sitúa la alquería de Lanteira y que, como dijimos al principio, abarcaba un total de ocho lugares, donde la compleja y dispersa fortificación de época islámica se sustituye por el castillo-palacio de La Calahorra, construido por los marqueses en el siglo XVI.

Para comprender adecuadamente el fenómeno de la fortificación rural en las tierras granadinas sería necesario hacer un inventario sistemático, incluyendo no sólo los restos existentes, sino también las torres que aparecen reflejadas en la documentación escrita. Además habría que relacionar estos datos con el volumen demográfico de la alquería y la frecuencia y cronología de incursiones castellanas en cada territorio. Se trataría de ver si son aquellas alquerías más pobladas las que tienen una capacidad suficiente para construir estas fortalezas o, en cambio, tiene

\footnotetext{
36 Véase nota 7.

${ }^{37}$ Mármol Carvajal: Historia del rebelion..., p. 321.
} 


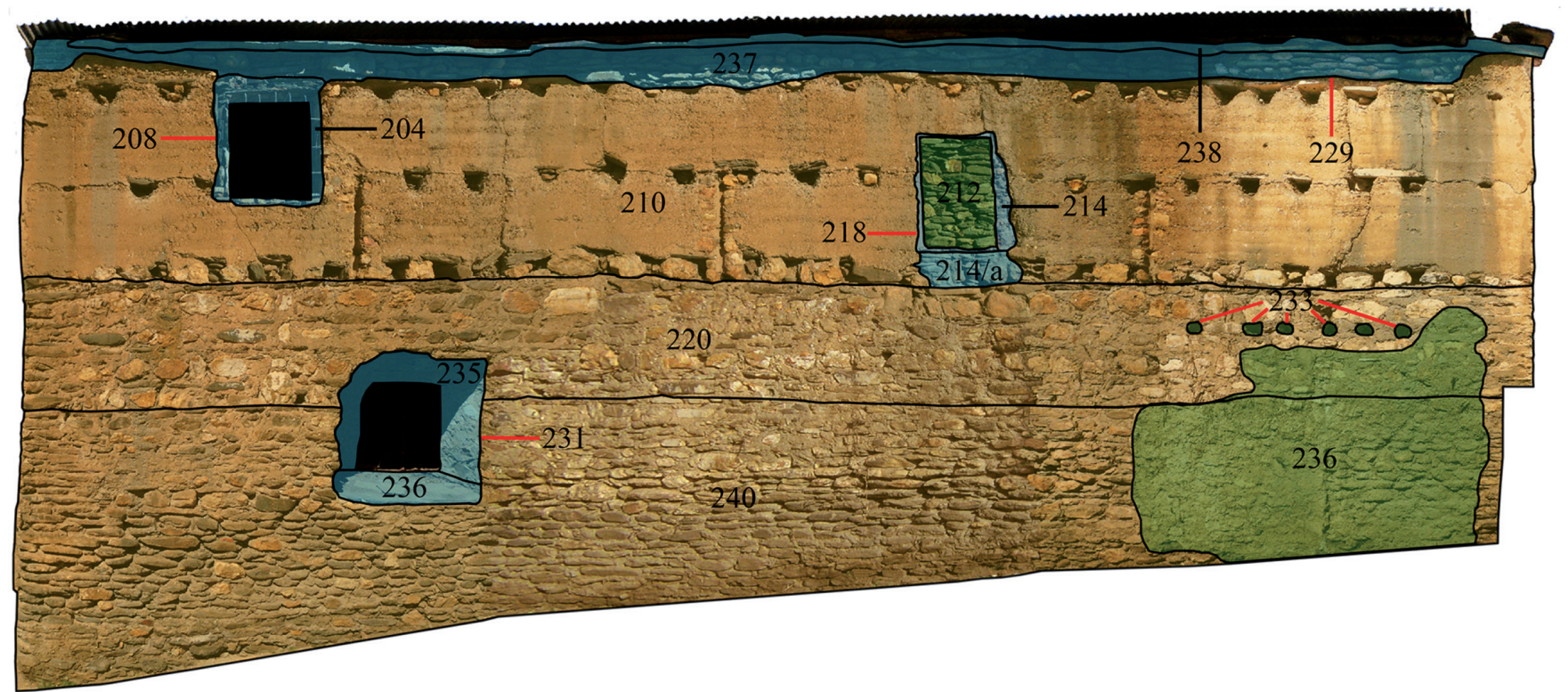

\section{PARAMENTO SUR}

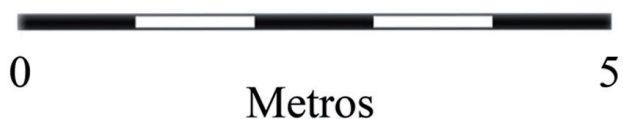

Siglos XIV - XV

Siglos XVI - XVIII

$1940-1960$

Fig. 25. Lectura estratigráfica del paramento sur de El Fuerte. En rojo están marcados las interfacies

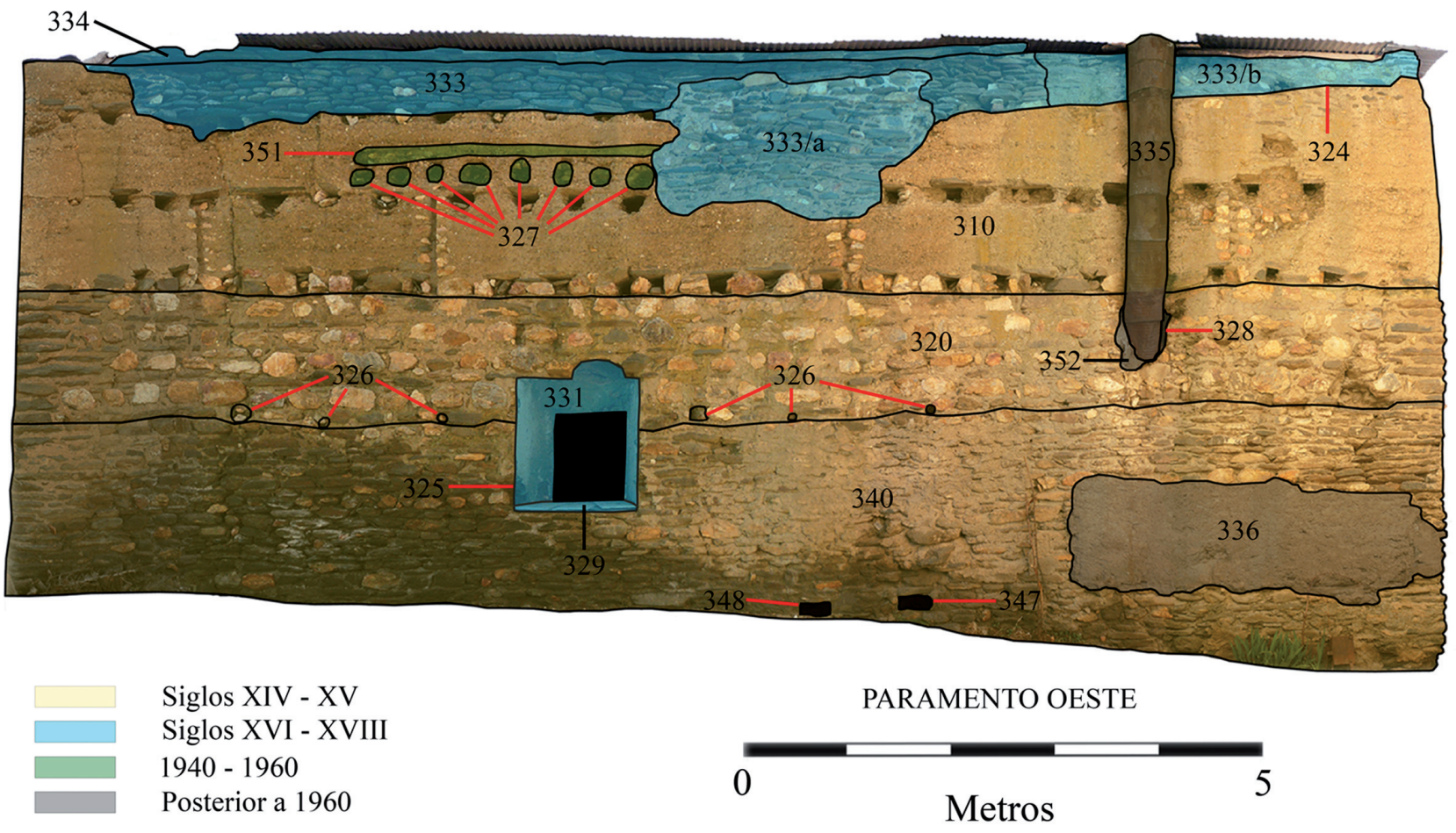

Fig. 26. Lectura estratigráfica del paramento oeste de El Fuerte. En rojo están marcados las itnerfacies 


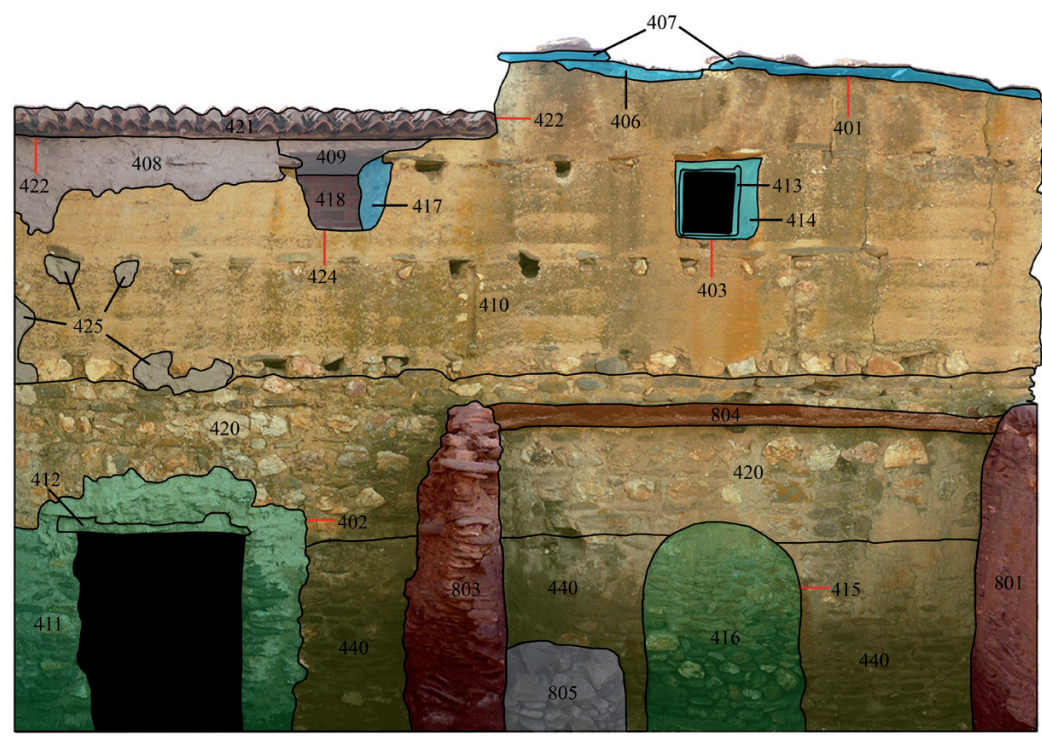

Siglos XIV - XV

Siglos XVI - XVIII Siglos XIX - Principios XX $1940-1960$ Posterior a 1960
PARAMENTO NORTE

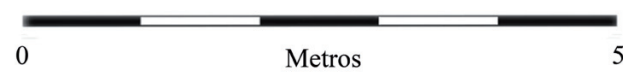

Fig. 27. Lectura estratigráfica del paramento norte de El Fuerte. En rojo están marcados las interfacies más importancia el factor fronterizo. En todo caso, deberíamos también relacionar toda esta información con la fortificación estatal, representada por alcazabas y castillos.

A falta de esta investigación, llama la atención el poco peso en el medio rural nazarí de los castillos ubicados en lugares prominentes, salvo en la frontera con Castilla. Un espacio rural que aparece controlado desde lejos por las alcazabas urbanas, pero que nos aparece cada vez más como un territorio fortificado con torres, a veces fortificaciones más complejas, que se sitúan junto a las casas de las alquerías. Probablemente esta proliferación, únicamente en momentos de inseguridad militar, se deba a que estas fortificaciones están despojadas de una determinada función jurisdiccional o económica, lo que hace que no supongan ninguna amenaza para el poder estatal. Al contrario, parecen servir de complemento a la organización defensiva que se estructura en torno a las ciudades.

En el caso de Guadix y su territorio observamos, por ejemplo, no sólo la influencia militar de la ciudad, sino también la intervención del juez de la ciudad, que ejerce un papel de arbitraje de los conflictos que surgen entre las diferentes alquerías, como en el caso de una disputa por dos montes entre Jérez y Lanteira en 1472, donde incluso el acuerdo final está refrendado por el cadí mayor de Gra$\operatorname{nada}^{38}$.

38 Ángel González Palencia: «Documentos árabes del Cenete (siglos XII-XV)», Al-Andalus, 5 (1940), pp. 301-382, espec. pp. 345-362.
Este hecho lleva a pensar que el territorio del reino nazarí está integrado por la suma de espacios regidos por una ciudad, salvo en zonas montañosas y de difíciles comunicaciones, como la Alpujarra, donde se mantienen los distritos rurales. Al frente de estos territorios dirigidos por una ciudad encontramos una élite político-militar, los alcaides o arraeces, que actúan por delegación del sultán, aunque son frecuentes las revueltas o traiciones, que se concretan muchas veces en la apuesta de los linajes insurgentes por otro miembro de la dinastía nazarí como candidato a emir de los granadinos, lo que da lugar a temporales fragmentaciones geográficas del reino ${ }^{39}$. A lo largo del siglo XV esta vertebración del espacio parece dar lugar a una cierta debilidad del poder central, por lo que se ha llegado a hablar de una situación de "poliarquía»" ${ }^{40}$. Pero, en cierto modo, no parece sino un proceso, no concluido totalmente, equivalente en gran medida al que se produce en al-Andalus con las primeras, segundas y terceras taifas, épocas de fragmentación del poder a nivel territorial que siguen a la crisis del

\footnotetext{
${ }^{39}$ Para la historia del reino nazarí de Granada sigue siendo fundamental el libro de Miguel Ángel Ladero Quesada: Granada. Historia de un país islámico (12321571), Granada, 1989. Sobre el papel de los linajes militares en el mundo nazarí, algunas reflexiones a partir del caso de la ciudad de Loja en Miguel Jiménez Puertas, Linajes y poder en la Loja islámica. De los Banu Jalid a los Alatares (siglos VIII-XV), Granada, 2009, pp. 169-203.

${ }^{40}$ Antonio Peláez Rovira: El Emirato nazari de Granada en el siglo XV. Dinámica politica y fundamentos sociales de un estado andalusí, Granada, 2009, pp. 182-191.
} 
poder centralizado representado por los omeyas, almorávides y almohades.

En todos estos procesos, el papel de las alquerías y sus fortificaciones parece secundario, aunque apunta también a una cierta descentralización ${ }^{41}$. Por el momento, la impresión que nos aportan construcciones como la de El Fuerte es la de una idea común en su construcción, en lo que se refiere a su emplazamiento dentro de las alquerías y a la tipología, pero una enorme diversidad en lo que se refiere a sus tamaños, plano exacto y técnicas constructivas. Es cierto que estas variaciones reflejan una cierta autonomía frente al poder centralizado, pero no parecen constituir sino una respuesta provisional a la violencia, que no exime de una dependencia de la ciudad, dado que en los momentos de graves conflictos es habitual que las mujeres y los niños se refugien tras las murallas de la ciudad más cercana, como ocurrió en la alquería de Tájara en 1483, quedando en la fortaleza sólo los varones adultos ${ }^{42}$. Esta vinculación se constata por los datos que tenemos sobre el mantenimiento de las fortalezas urbanas, como en el caso de Salobreña, donde las alquerías participan en la reparación de las murallas de la ciudad ${ }^{43}$, lo cual tiene una doble interpretación, por una parte subordinación a la ciudad y al poder político, pero por otra parte insuficiencia de la alquería para defenderse por sus propios medios.

Siguiendo esta línea de interpretación, podemos pensar que el sultán, pero sobre todo los grandes alcaides de las ciudades, tal vez no hubieran permitido la existencia de fortificaciones rurales que hagan sombra a las alcazabas urbanas, por lo cual la aprobación de la autoridad políticomilitar debió ser un requisito necesario para la construcción de estas fortalezas rurales, mantenidas siempre dentro de una limitada capacidad defensiva. Como hemos dicho, su proliferación evidencia que estaban despojadas de cualquier función que pudiera amenazar al poder político. Por otra parte, frente a los notables conflictos que implican en época nazarí a los miembros de la familia real y a los más importantes linajes aristocráticos, destaca la ausencia de noticias sobre sublevaciones internas que se amparen en estas u otras fortalezas rurales, aunque encontremos resistencias a la imposición de nuevos tributos. En este sentido, habría que recordar que Ibn al-Jatib, visir granadino del siglo XIV, destacaba entre las cualidades de los habitantes del reino las siguientes: "Su obediencia a los emires es perfecta y su conducta en soportar las cargas tributarias es admirable» ${ }^{44}$. Quizá esta actitud de adhesión al Estado tenga que ver, en estos momentos finales del Islam en la península, con un consenso interno y con una movilización de todos los recursos posibles, de cara a ofrecer una respuesta más eficaz a la fuerte presión militar castellana, que en cualquier caso resultó insuficiente.

Recibido: 19 de octubre de 2010 Aceptado: 22 de noviembre de 2010

\footnotetext{
${ }^{41}$ La idea de las torres de alquería como símbolos descentralizadores ha sido planteada también para la campiña cordobesa en época almohade: Francisco Sánchez Villaespesa «Las torres de la Campiña de Córdoba en el siglo XIII. Un sistema de defensa de las comunidades rurales en época almohade» en Qurtuba, estudios andalusies, 1 (1996), pp. 157-170.

${ }^{42}$ Una relación de la conquista y destrucción de Tájara, alquería del territorio de Loja, en Duquesa de Berwick y de Alba: Documentos escogidos del Archivo de la Casa de Alba, Madrid, 1891, pp. 24-32.

${ }^{43}$ Antonio Malpica Cuello: Medio fisico y poblamiento en el delta del Guadalfeo. Salobreña y su territorio en época medieval, Granada, 1996, p. 138.
}

${ }^{44}$ Ibn al-Jațîb: al-Lamha al-badriyya, trad. J.M. Casciaro, Granada, 1998, p. 31. 